\title{
Biochar modification to enhance sorption of inorganics from water
}

\section{Article}

\section{Accepted Version}

Creative Commons: Attribution-Noncommercial-No Derivative Works 4.0

Sizmur, T., Fresno, T., Akgül, G., Frost, H. and MorenoJiménez, E. (2017) Biochar modification to enhance sorption of inorganics from water. Bioresource Technology, 246. pp. 3447. ISSN 0960-8524 doi:

https://doi.org/10.1016/j.biortech.2017.07.082 Available at https://centaur.reading.ac.uk/71915/

It is advisable to refer to the publisher's version if you intend to cite from the work. See Guidance on citing.

Published version at: https://doi.org/10.1016/j.biortech.2017.07.082

To link to this article DOI: http://dx.doi.org/10.1016/j.biortech.2017.07.082

Publisher: Elsevier

All outputs in CentAUR are protected by Intellectual Property Rights law, including copyright law. Copyright and IPR is retained by the creators or other copyright holders. Terms and conditions for use of this material are defined in the End User Agreement.

\section{www.reading.ac.uk/centaur}

\section{CentAUR}

Central Archive at the University of Reading 
Reading's research outputs online 


\title{
Biochar modification to enhance sorption of inorganics from water
}

Tom Sizmur ${ }^{1}$, Teresa Fresno ${ }^{2}$, Gökçen Akgül ${ }^{3}$, Harrison Frost ${ }^{1}$, Eduardo Moreno Jiménez ${ }^{2 *}$

\author{
${ }^{l}$ Department of Geography and Environmental Science, University of Reading, Reading, RG6 6DW, UK \\ ${ }^{2}$ Department of Agricultural and Food Chemistry, Faculty of Sciences, Universidad Autonoma de Madrid, 28049, Madrid, \\ Spain \\ ${ }^{3}$ Recep Tayyip Erdogan University, Engineering Faculty, Department of Energy Systems Engineering, 53100, Rize, Turkey
}

*Corresponding author: Eduardo Moreno Jiménez, Department of Agricultural and Food Chemistry, Faculty of Sciences, Universidad Autonoma de Madrid, 28049, Madrid, Spain. Phone: +34914978470 ; email: eduardo.moreno@uam.es

\begin{abstract}
Biochar can be used as a sorbent to remove inorganic pollutants from water but the efficiency of sorption can be improved by activation or modification. This review evaluates various methods to increase the sorption efficiency of biochar including activation with steam, acids and bases and the production of biochar-based composites with metal oxides, carbonaceous materials, clays, organic compounds, and biofilms. We describe the approaches, and explain how each modification alters the sorption capacity. Physical and chemical activation enhances the surface area or functionality of biochar, whereas modification to produce biochar-based composites uses the biochar as a scaffold to embed new materials to create surfaces with novel surface properties upon which inorganic pollutants can sorb. Many of these approaches enhanced the retention of a wide range of inorganic pollutants in waters, but here we provide a comparative assessment for $\mathrm{Cd}^{2+}, \mathrm{Cu}^{2+}, \mathrm{Hg}^{2+}, \mathrm{Pb}^{2+}, \mathrm{Zn}^{2+}, \mathrm{NH}_{4}{ }^{+}, \mathrm{NO}_{3}{ }^{-}, \mathrm{PO}_{4}{ }^{3-}, \mathrm{CrO}_{4}{ }^{2-}$ and $\mathrm{AsO}_{4}{ }^{3-}$.
\end{abstract}

Keywords: Modification, sorption, inorganic, pollution, activation 


\section{Introduction}

Biochar is produced by heating organic materials in the partial or total absence of oxygen (pyrolysis). The objective of biochar production is usually to generate energy or to reduce the mass or volume of waste materials. However, considerable interest has been paid to optimising the pyrolysis conditions to improve the yield (Tripathi et al., 2016) and properties (Mukherjee et al., 2011) of the resulting biochar. Biochar is resistant to degradation, has a high surface area and a considerable negative charge (Sizmur et al., 2016). It has therefore been proposed as a sustainable means to remove positively charged ions (e.g. $\mathrm{Cd}^{2+}, \mathrm{Cu}^{2+}$, $\mathrm{Pb}^{2+}, \mathrm{Zn}^{2+}$ ) and polar organic molecules (e.g. phenolics, halogenated compounds, solvents) from water by ion exchange, electrostatic attraction, physical sorption and precipitation (Tan et al., 2015).

There are several methodologies by which the properties of biochar can be chemically, physically or biologically modified by treating the feedstock or, more commonly, the resulting biochar (Rajapaksha et al., 2016). These methodologies include treatments with steam, acids, bases, metal oxides, carbonaceous materials, clay minerals, organic compounds, and biofilms. The objectives of these treatments are broadly to either, (i) increase the surface area of the biochar, (ii) modify or enhance the surface properties of the biochar, or (iii) use the surface as a platform to embed another material (or organism) with beneficial surface properties. The tools available to modify biochars increase the breadth of chemical pollutants which can be removed from water using biochar.

This review will provide an introduction to common inorganic pollutants, describe the surface properties of unmodified biochar, introduce the various modification approaches, explain how the pyrolysis process and the modifications alter the surface properties of biochar, and demonstrate how these modifications enhance the removal of inorganic contaminants from aqueous solutions. 


\section{Common inorganic pollutants in water}

The prevention and remediation of freshwater pollution is one of the greatest global challenges facing humanity in the $21^{\text {st }}$ century (Dudgeon et al., 2006). Anthropogenic disruption of biogeochemical cycling of elements has increased the concentrations, or changed the chemical form, of several elements in terrestrial ground and surface waters. The inorganic contaminants of primary concern are classified by their chemical behavior and discussed below. Efficient, sustainable, and cost-effective remediation strategies for these elements are urgently required.

Potentially toxic elements, such as $\mathrm{As}, \mathrm{Cd}, \mathrm{Cr}, \mathrm{Cu}, \mathrm{Hg}, \mathrm{Pb}$ and $\mathrm{Zn}$ are often present discharges from mining and smelting, sewage treatment, road runoff and the manufacture of batteries, pigments and dyes, electronics and alloys (Moore \& Ramamoorthy, 2012). In sufficient concentrations, these elements can cause ecotoxicological effects to freshwater ecology and can bioaccumulate through food webs resulting in chronic toxicity to higher tropic levels, including humans. Most of these elements $(\mathrm{Cd}, \mathrm{Cu}, \mathrm{Hg}, \mathrm{Pb}$, and $\mathrm{Zn})$ occur primarily in the environment as divalent cations. $\mathrm{Cd}$ and $\mathrm{Zn}$ have a larger radius and thus a lower charge-toradius ratio and lower ionic potential than $\mathrm{Cu}, \mathrm{Hg}$ and $\mathrm{Pb}$. For this reason, $\mathrm{Cu}, \mathrm{Hg}$ and $\mathrm{Pb}$ more readily form bonds with functional groups on surfaces and are thus less mobile than $\mathrm{Cd}$ and $\mathrm{Zn}$.

Concentrations of nutrients $\left(\mathrm{NH}_{4}{ }^{+}, \mathrm{NO}_{3}{ }^{-}\right.$and $\left.\mathrm{PO}_{4}{ }^{3-}\right)$ are elevated in surface and ground waters globally, largely due to sewage effluent and inefficient application of agricultural fertilizers, (Mueller \& Helsel, 1996). The elevated nutrient status of freshwater discharges to oceans causes ecological damage in estuaries and coastal zones by promoting harmful algal blooms, and reducing dissolved oxygen concentrations, resulting hypoxic 'dead zones' (Conley et al., 2009). 
While $\mathrm{NH}_{4}{ }^{+}$is positively charged and is attracted to the negatively charged surfaces, it has a much lower charge-to-radius ratio than the metal cations discussed above. $\mathrm{NH}_{4}{ }^{+}$thus behaves similarly to alkali metal cations (e.g. $\mathrm{Na}^{+}, \mathrm{K}^{+}$) and so does not form as stable bonds with surfaces as the divalent metal cations. Unlike $\mathrm{NH}_{4}{ }^{+}, \mathrm{NO}_{3}{ }^{-}$and $\mathrm{PO}_{4}{ }^{3-}$ are oxyanions with contrasting behavior to each other. Both are negatively charged and therefore attracted to positively charged surfaces but $\mathrm{NO}_{3}{ }^{-}$is much more mobile than $\mathrm{PO}_{4}{ }^{3-}$, which readily binds to colloids in water.

As and $\mathrm{Cr}$ are redox sensitive elements that exhibit contrasting changes to mobility and toxicity in response to changes in redox conditions. Inorganic As can be found in the environment as pentavalent arsenate, $\mathrm{As}(\mathrm{V})$, or as trivalent arsenite, $\mathrm{As}(\mathrm{III})$. Arsenate $\left(\mathrm{AsO}_{4}{ }^{3-}\right.$ ) is found in aerobic environments, and arsenite $\left(\mathrm{AsO}_{3}{ }^{3-}\right)$, which is more toxic to humans, is more mobile, and occurs in anaerobic conditions, including groundwater (Moore \& Ramamoorthy, 2012). The use of naturally occurring As contaminated groundwater as drinking water and to irrigate rice paddies has resulted in widespread poisoning of human populations, especially in Bangladesh. $\mathrm{Cr}$ can be found as trivalent $\mathrm{Cr}$ (III) and hexavalent $\mathrm{Cr}(\mathrm{VI})$. In contrast to As, the reduced species, $\mathrm{Cr}(\mathrm{III})$ is considered a beneficial element in humans as it enhances insulin production, whereas $\mathrm{Cr}(\mathrm{VI})$, usually present as chromate $\left(\mathrm{CrO}_{4}{ }^{2-}\right)$ or dichromate $\left(\mathrm{Cr}_{2} \mathrm{O}_{7}{ }^{2-}\right)$ is a strong oxidising agent, is carcinogenic, and is more mobile and much more toxic than $\mathrm{Cr}(\mathrm{III})$ (Kotaś \& Stasicka, 2000). Chromium most notoriously contaminates surface waters due to discharge of tannery effluent .

To reduce the concentrations of these inorganic contaminants of concern in aquatic ecosystems it is essential to treat point source discharges of agricultural, domestic and industrial wastewater before disposal into the freshwater environment. Current wastewater treatment technologies to remove inorganic contaminants are costly, energy intensive, and require disposal of resulting toxic waste (Shannon et al., 2008). These limitations of the 
currently available technologies provide a demand for an efficient, selective, cost-effective adsorbent material. The modification of biochar could provide the versatile, low cost and sustainable solution to point source pollution of freshwater with inorganic pollutants.

\section{How biochar properties influence the sorption of inorganic pollutants from} aqueous solutions

Biochar can be used as a sorbent to remove pollutants from water and may be removed from solution when saturated, treated appropriately and replaced with new or recycled biochar. There are several mechanisms responsible for the high sorption capacity of biochar for specific pollutants.

Biochars have a high surface area due to a large distribution of micro or mesopores. The greater the number of micropores, the greater the surface area of the biochar and the more surface sites upon which pollutants can adsorb. Several authors have observed a relationship between pollutant adsorption capacities and biochar surface area (Kim et al., 2013; Tan et al., 2015).

Surface functionality also affects biochar sorption capacity (Fletcher et al., 2014; Niu et al., 2017). Sorption of inorganic pollutants by biochar is a result of (i) stoichiometric ionic exchange, (ii) electrostatic attraction, or (iii) surface precipitation (Beesley et al., 2015; Gomez-Eyles et al., 2013; Sizmur et al., 2016).

(i) Chemical sorption occurs due to ion exchange with the abundant functional groups on the carbonaceous surface of biochar, such as carboxylic, hydroxylic or phenolic groups (Lee et al., 2010; Liang et al., 2006). These groups confer cation exchange capacity (CEC) to biochar depending on feedstock and pyrolysis temperature, with a peak of CEC at around $350-400{ }^{\circ} \mathrm{C}$ (Gomez-Eyles et al., 2013), probably due to the loss of oxygenated functional groups above this temperature (Lee et al., 2010). Chemical sorption of cations relies on releases of protons and base cations (Na, K, Ca or Mg) from the biochar (Uchimiya et al., 2010). Since chemical 
sorption is stoichiometric, sorption efficiency is $\mathrm{pH}$ dependent and thus dictated by the $\mathrm{pH}$ of the medium.

(ii) Physical (electrostatic) sorption occurs between positively charged ions in water and the delocalised cloud of electrons associated with aromatic groups on the surface of carbonaceous biochars, creating cation- $\pi$ interactions with the $C=C$ aromatic bonds (Harvey et al., 2011). Unlike chemical sorption, physical adsorption does not require stoichiometric release of cations or protons from the biochar.

(iii) Precipitation (or co-precipitation) of inorganic pollutants (particularly metal cations) with insoluble salts occurs on the surface of biochars with a high mineral ash content. For example, precipitation of $\mathrm{Pb}$ has been demonstrated on the surface of phosphate rich biochars derived from manures (Cao et al., 2009). Biochar may also raise the $\mathrm{pH}$ of the solution (depending on its starting $\mathrm{pH}$ ), leading to the precipitation of metal (hydr)oxides, which are generally sparingly soluble.

Surface area and functionality can be manipulated by the modification of biochar to enhance sorption capacities for specific pollutants. Modifications often have the objective of increasing the anion sorption capacity while activation usually increases the metal cation sorption capacity of biochars. However, considerable differences in the surface area and functionality of biochars can result from altering the pyrolysis temperature.

\section{Effect of pyrolysis temperature on biochar properties and sorption capacity}

Although modifications of biochars (post-pyrolysis) or their feedstocks (pre-pyrolysis) can alter their physico-chemical properties, pyrolysis conditions can also affect the biochar structure and composition and thus its metal sorption capacity (Figure 1). Pyrolysis temperature influences the adsorption characteristics of biochar by changing the surface area,

surface functionality, pore distribution and mineral concentration of biochar (Ahmad et al., 
2012; Chen et al., 2014; Jung et al., 2016b; Kim et al., 2012). It is important to produce biochar at optimum pyrolysis temperatures to maximise inorganic contaminant adsorption.

The development of microstructure and an increase in the surface area of biochar upon increasing pyrolysis temperature has been widely observed, regardless of the feedstock used (Cantrell et al., 2012; Fletcher et al., 2014; Uchimiya et al., 2010). Fletcher et al. (2014) observed an opening of the internal structure when the pyrolysis temperature of willow biochar was $\geq 450^{\circ} \mathrm{C}$. At higher temperature $\left(\geq 550^{\circ} \mathrm{C}\right)$, the width of mesopores increased and new micropores were created. However, Jung et al. (2016b) found a decrease in total pore volume, surface area and phosphate sorption capacity of a biochar produced from a marine macroalgae when pyrolysis temperature increased to 600 and $800{ }^{\circ} \mathrm{C}$, likely due to blockage and collapse of the pore structures (Paethanom \& Yoshikawa, 2012) by melting of the material during pyrolysis.

Biochars produced at higher temperatures often contain greater amounts of $\mathrm{C}$ fixed in the biochar structure (i.e. higher $\mathrm{C}$ content) as a result of greater loss of volatile matter at high pyrolysis temperatures (Cantrell et al., 2012; Kim et al., 2012). Increasing pyrolysis temperatures also increases the aromaticity and decreases the polarity of the biochar, so the biochar surface becomes less hydrophilic. Lower $\mathrm{O}$ and $\mathrm{H}$ contents have been reported when increasing pyrolysis temperature due to loss of surface functional groups. The decrease in oxygen-containing functional groups can affect the metals sorption capacity of biochars, as observed by Ding et al. (2014), who found higher Pb adsorption capacity of biochar when produced at lower temperature. The authors suggest that for lower temperature biochars, oxygen-containing functional groups were responsible for $\mathrm{Pb}$ sorption, whereas for high temperature biochars, $\mathrm{Pb}$ sorption was dominated by intraparticle diffusion and was thus affected by the abundant pores. 


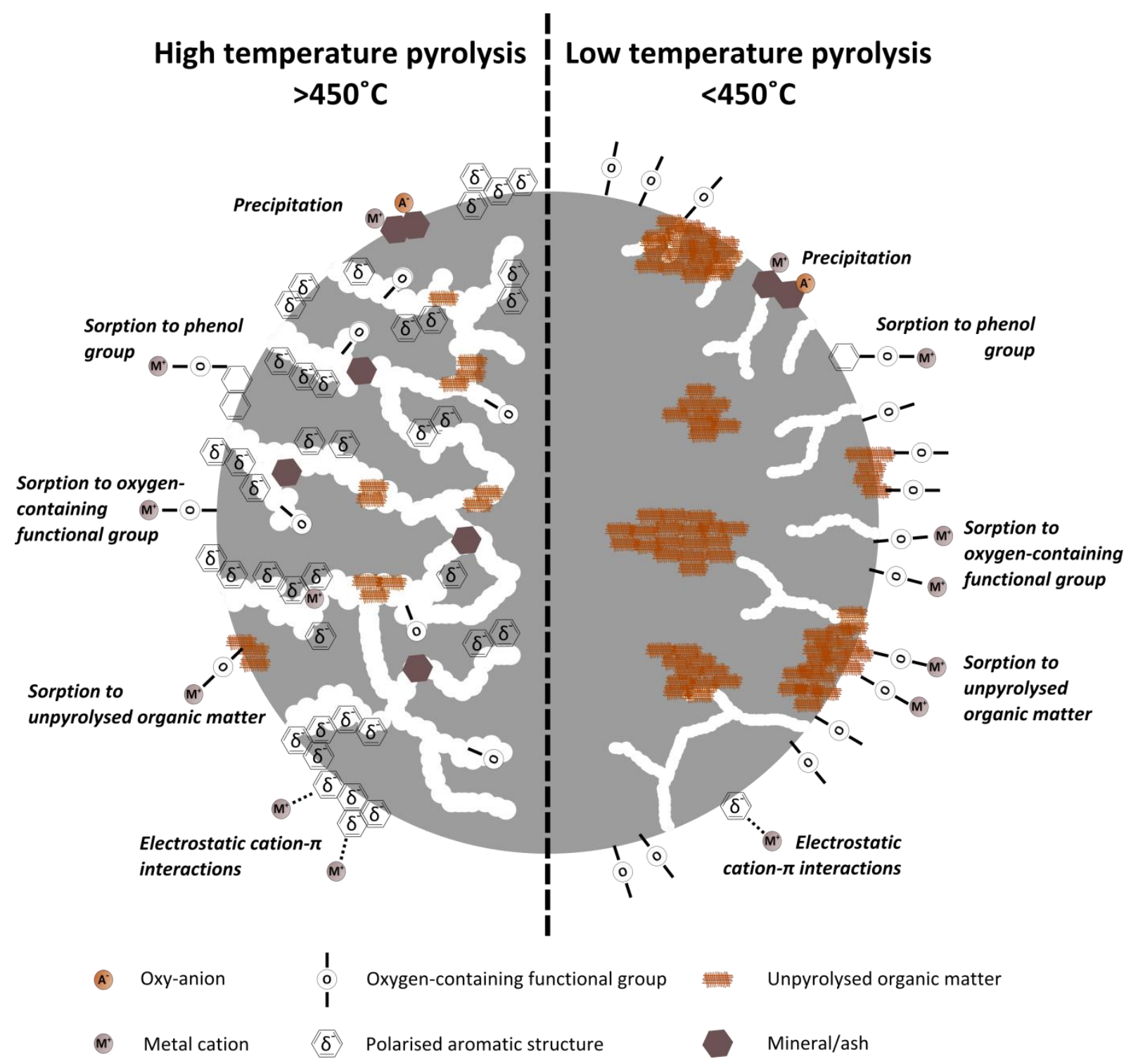

Figure 1. Conceptual model identifying the mechanisms of metal cation (e.g. $\mathrm{Cd}^{2+}$, $\mathrm{Cu}^{2+}, \mathrm{Hg}^{2+}, \mathrm{Pb}^{2+}, \mathrm{Zn}^{2+}$ ) and oxyanion (e.g. $\mathrm{PO}_{4}{ }^{3-}, \mathrm{AsO}_{4}{ }^{3-}$ ) sorption to biochar pyrolysed at high temperature $\left(>450^{\circ} \mathrm{C}\right)$ and low temperature $\left(<450^{\circ} \mathrm{C}\right)$. High temperature biochar has a higher surface area, pores previously blocked by unpyrolysed organic matter are unblocked, and there are more aromatic groups and less oxygen containing functional groups on the biochar surface.

The yield of biochar production decreases as pyrolysis temperature increases, generally by about $10 \%$ for every temperature increase of $100{ }^{\circ} \mathrm{C}$ (Chen et al., 2014; Fletcher et al., 2014). As the pyrolysis temperature increases and the biochar yield decreases, the mineral ash content becomes more concentrated. Consequently, biochars produced at higher pyrolysis temperatures have more total, soluble and exchangeable base cations and carbonates, less 
oxygenated functional groups and greater pH (Fletcher et al., 2014; Qian et al., 2013; Yuan et al., 2011). Thus, more alkaline biochar can be produced by increasing the pyrolysis temperature, which can lead to greater precipitation of metal cations (Kim et al., 2013). Chen et al. (2014) reported higher Cd removal from an aqueous solution by biochar produced with a mixture of sewage sludge and pine bark when biochar was produced at higher pyrolysis temperature. The authors suggested that $\mathrm{Cd}^{2+}$ sorption onto biochar was likely due to surface precipitation with $\mathrm{Ca}^{2+}$ and thus attributed the higher $\mathrm{Cd}$ removal to the enhanced cation exchange capacity in higher temperature-biochar due to concentrated alkaline-earth metals, such as $\mathrm{Ca}^{2+}$, in the ash during pyrolysis.

\section{Methods of modifying Biochar}

Innovative methodologies for modifying biochar have been developed to enhance the adsorption of inorganic pollutants from water. Modifications are performed either pre-or postpyrolysis of the biochar (or both). Whilst pre-pyrolysis modifications involve the treatment of the biochar feedstock, post-pyrolysis modifications are more common and involve the treatment of biochar after it has already been produced. Figure 2 provides a classification system of the most common modification methods reported in the literature. The physical activation of biochar using steam and chemical activation using acidic and alkaline solutions is usually undertaken post-pyrolysis, although promising results have been reported also when chemical activation is conducted pre-pyrolysis. The production of biochar-based composites, the modification method that has received the most research attention for creating sorbents for remediation of polluted waters, is performed by embedding different materials into the biochar structure pre- or post-pyrolysis. The primary aim of all these modification methods is to enhance the efficacy by which the biochar removes pollutants from water, generally by changing its physical or chemical properties, such as surface area, or surface functionality. 


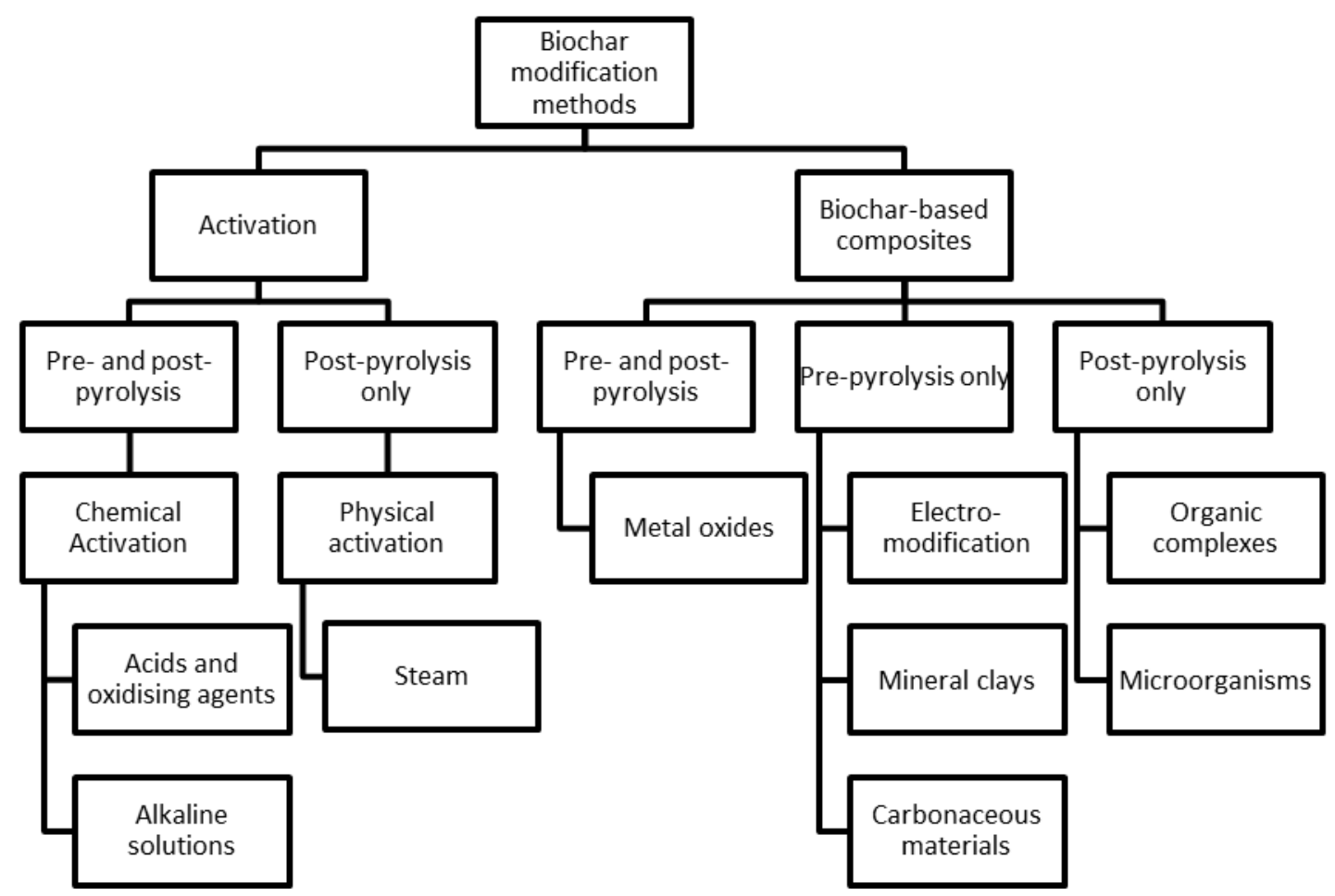

Figure 2. Chart defining a classification system of biochar modification methods to physically and chemically activate biochars and produce biochar based composites

The properties of biochar can be altered by physical and chemical activation. While the acid and alkali treatments are the most common chemical activation methods, steam is the primary physical activation method. Biochar-based composites are prepared by impregnation or coating the surface of the biochar with metal oxides (Micháleková-Richveisová et al., 2017), clay minerals (Chen et al., 2017), carbonaceous structures such as graphene oxide (Shang et al., 2016) or carbon nanotubes (Inyang et al., 2015), complex organic compounds, such as chitosan (Zhou et al., 2013) or amino acids (Yang \& Jiang, 2014), or inoculation with microorganisms (Frankel et al., 2016). These modification methods are explained in detail in the following sections and their impact on the sorption of selected inorganic pollutants in water are summarised in Table 1. 
Table 1. Effect of biochar modifications on common inorganic pollutants in water. The modifications were sorted as Physical activation with steam (Phy. A. - Steam); Chemical activation with acids or oxidants (Ch. A. - Acids/oxidants) or with bases (Ch. A. Acids/oxidants); Biochar-based composites (Comp.) modified with metals (Metals), carbonaceous materials (C materials), electrical field (Electromodified), organic molecules (Organics) and Biofilms (microorganisms).

\begin{tabular}{|c|c|c|c|c|c|}
\hline Target pollutant & Type of biochar modification & Treatment / Feedstock & Treatment stage & $\begin{array}{l}\text { Effect on metal } \\
\text { sorption capacity }\end{array}$ & References \\
\hline \multirow[t]{5}{*}{$\mathrm{Cd}^{2+}$} & Phy. A. - Steam & Steam / Poultry manure) & Post-pyrolysis & + & Lima and Marshall (2005) \\
\hline & Ch. A. - Bases & $\mathrm{KOH} /$ Ipomoea biomass & Post-pyrolysis & + & Goswami et al., (2016) \\
\hline & Comp. - Metals & Fe / Several feedstocks & Post-pyrolysis & + & $\begin{array}{l}\text { Mohan et al., (2014); } \\
\text { Trakal et al., (2016) }\end{array}$ \\
\hline & Comp. - Organics & $\begin{array}{l}\text { Chitosan / Bamboo, hickory wood, } \\
\text { sugarcane bagasse }\end{array}$ & Post-pyrolysis & + & Zhou et al., (2013) \\
\hline & Comp. - Organics & Chitosan / Peanut hull & Post-pyrolysis & - & Zhou et al., (2013) \\
\hline $\mathrm{Zn}^{2+}$ & Phy. A. - Steam & Steam / poultry manure & Post-pyrolysis & + & Lima and Marshall (2005) \\
\hline \multirow[t]{7}{*}{$\mathrm{Cu}^{2+}$} & Phy. A. - Steam & Steam / Pine sawdust & Post-pyrolysis & $=$ & Lou et al., (2016) \\
\hline & Phy. A. - Steam & Steam / poultry manure & Post-pyrolysis & + & Lima and Marshall (2005) \\
\hline & Ch. A. - Acids/oxidants & $\mathrm{HNO}_{3} /$ Cactus cladodes & Post-pyrolysis & + & Hadjitoffi et al., (2014) \\
\hline & Ch. A. - Bases & $\mathrm{KOH} /$ Fruit peel & Post-pyrolysis & + & Hamid et al., (2014) \\
\hline & Comp. - Metals & Mn / Corn straw & Post-pyrolysis & + & Song et al., (2014) \\
\hline & Comp. - Organics & $\begin{array}{l}\text { Amino-modification by nitrification and } \\
\text { reduction / Commercial sawdust }\end{array}$ & Post-pyrolysis & + & Yang and Jiang, (2014) \\
\hline & Comp. - Organics & $\begin{array}{l}\text { Chitosan / Bamboo, hickory wood, } \\
\text { sugarcane bagasse, peanut hull }\end{array}$ & Post-pyrolysis & - & Zhou et al., (2013) \\
\hline $\mathrm{Hg}^{2+}$ & Comp. - C materials & Graphene oxide / Wheat straw & Pre-pyrolysis & + & Tang et al., (2015) \\
\hline \multirow[t]{5}{*}{$\mathrm{Pb}^{2+}$} & Ch. A. - Acids/oxidants & $\mathrm{H}_{3} \mathrm{PO}_{4} /$ Pine sawdust & Pre-pyrolysis & + & Zhao et al., (2017) \\
\hline & Ch. A. - Acids/oxidants & $\mathrm{H}_{2} \mathrm{O}_{2}$ / Peanut hull hydrochar & $\begin{array}{l}\text { Post-hydrothermal } \\
\text { treatment }\end{array}$ & + & Xue et al., (2012) \\
\hline & Comp. - Metals & Mn / Pine wood & Pre-pyrolysis & + & Wang et al., (2015a) \\
\hline & Comp. - Metals & Mn / Pine wood & Post-pyrolysis & + & Wang et al., (2015a) \\
\hline & Comp. - Metals & Fe / Several feedstocks & Post-pyrolysis & + & $\begin{array}{l}\text { Mohan et al.,(2014); } \\
\text { Trakal et al., (2016) }\end{array}$ \\
\hline
\end{tabular}




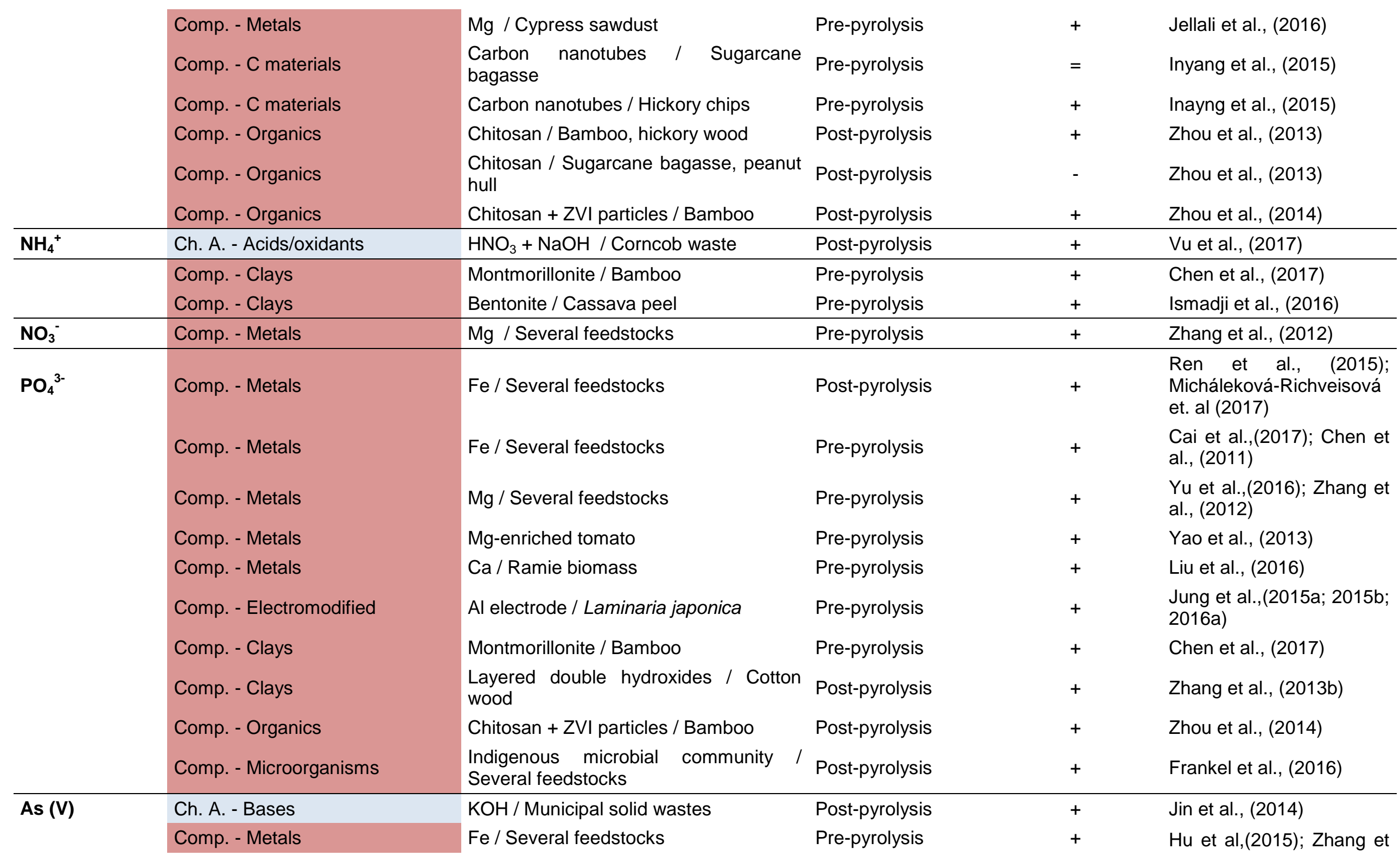




\begin{tabular}{|c|c|c|c|c|c|}
\hline & \multirow[b]{2}{*}{ Comp. - Metals } & \multirow[b]{2}{*}{ Fe / Several feedstocks } & \multirow[b]{2}{*}{ Post-pyrolysis } & \multirow[b]{2}{*}{+} & $\begin{array}{l}\text { al.,(2016); Zhang et al., } \\
\text { (2013a) }\end{array}$ \\
\hline & & & & & $\begin{array}{l}\text { Agrafioti et al.,(2014); } \\
\text { Fristak et al.,(2017); } \\
\text { Wang et al.,(2015b); } \\
\text { Wang et al., (2017b) }\end{array}$ \\
\hline & Comp. - Metals & Magnetic gelatin / Chestnut shell & Post-pyrolysis & + & Zhou et al., (2017b) \\
\hline & Comp. - Metals & Al / Several feedstocks & Pre-pyrolysis & + & Zhang and Gao, (2013) \\
\hline & Comp. - Metals & Mn / Pine wood & Pre-pyrolysis & + & Wang et al.,(2015a); \\
\hline & Comp. - Metals & Mn / Pine wood & Post-pyrolysis & + & Wang et al.,(2015a); \\
\hline & Comp. - Metals & $\mathrm{Mn}+\mathrm{Ni} /$ Pine wood & $\begin{array}{l}\text { Pre- and post- } \\
\text { pyrolysis }\end{array}$ & + & Wang et al., (2016) \\
\hline & Comp. - Organics & Chitosan + ZVI particles / Bamboo & Post-pyrolysis & + & Zhou et al., (2014) \\
\hline & Comp. - Microorganisms & $\begin{array}{l}\text { Indigenous microbial community } \\
\text { Several feedstocks }\end{array}$ & Post-pyrolysis & + & Frankel et al., (2016) \\
\hline & Comp. - Metals & Fe / Rice straw & Post-pyrolysis & + & $\begin{array}{l}\text { Quian et al.,(2017); Wang } \\
\text { et al., (2017a) }\end{array}$ \\
\hline & Comp. - Metals & Fe / Eucalyptus & Post-pyrolysis & - & Wang et al., (2014) \\
\hline \multirow[t]{4}{*}{$\mathrm{Cr}(\mathrm{VI})$} & Comp. - C materials & Graphene oxide / Hyancith & Pre-pyrolisis & + & Shang et al., (2016) \\
\hline & Comp. - Organics & Ployethylenimine-methanol / Rice husk & Post-pyrolysis & + & Ma et al., (2014) \\
\hline & Comp. - Organics & $\begin{array}{l}\text { Chitosan / Fe-treated Eichhornia } \\
\text { crassipes }\end{array}$ & Post-pyrolysis & + & Zhang et al., (2015) \\
\hline & Comp. - Organics & Chitosan + ZVI particles / Bamboo & Post-pyrolysis & + & Zhou et al., (2014) \\
\hline
\end{tabular}


259 The activation of biochar involves the use of steam or acidic or alkaline solutions to create a network of interconnecting micropores that ultimately increases the surface area upon which metal cations can chemically or physically adsorb. Physical activation methods force high temperature steam through the pores of the biochar, which increases the surface area, while chemical activation methods expose the biochar to acidic or alkaline solutions which oxidise the surface and create oxygen-containing functional groups (Figure 3).

\subsubsection{Physical activation}

\subsubsection{Steam}

\section{7}

Steam activation is a common modification method used to increase the structural porosity of the biochar and remove impurities such as products of incomplete combustion. This treatment serves to increase the surface area upon which sorption can occur. Lima and Marchall (2005) produced activated biochars from poultry manure feedstocks by pyrolysing at $700{ }^{\circ} \mathrm{C}$ followed by steam activation at $800{ }^{\circ} \mathrm{C}$ with a range of water flow rates and durations. Higher flow rates and longer activation times increased the sorption of $\mathrm{Cd}, \mathrm{Cu}$ and $\mathrm{Zn}$ on the surface 273 of the biochar.

274 Although steam activation increases the surface area and porosity of biochar, Shim et al. 275 (2015) found that the $\mathrm{Cu}^{2+}$ sorption capacity of biochar produced by slow pyrolysis of Miscanthus at $500{ }^{\circ} \mathrm{C}$ was not significantly changed by activation with steam at $800^{\circ} \mathrm{C}$. They

277 found that although steam activation of the biochar increased the surface area, the abundance 278 of functional groups decreased, alongside an increase in aromaticity. Similarly, Lou et al. 279 (2016) observed that steam activation of biochar prepared with pine sawdust increased the 280 surface area but had little effect on the characteristics of surface functional groups. The steam treatment did not affect adsorption capacity for phosphate due to electrostatic repulsion by the 
surface area of biochar.

\section{Unactivated biochar}

Pores blocked by unpyrolysed organic matter and mineral ash

Sorbtion due to:

- Electrostatic cation- $\pi$ interations

- Oxygen-containing functional groups

- Precipitation

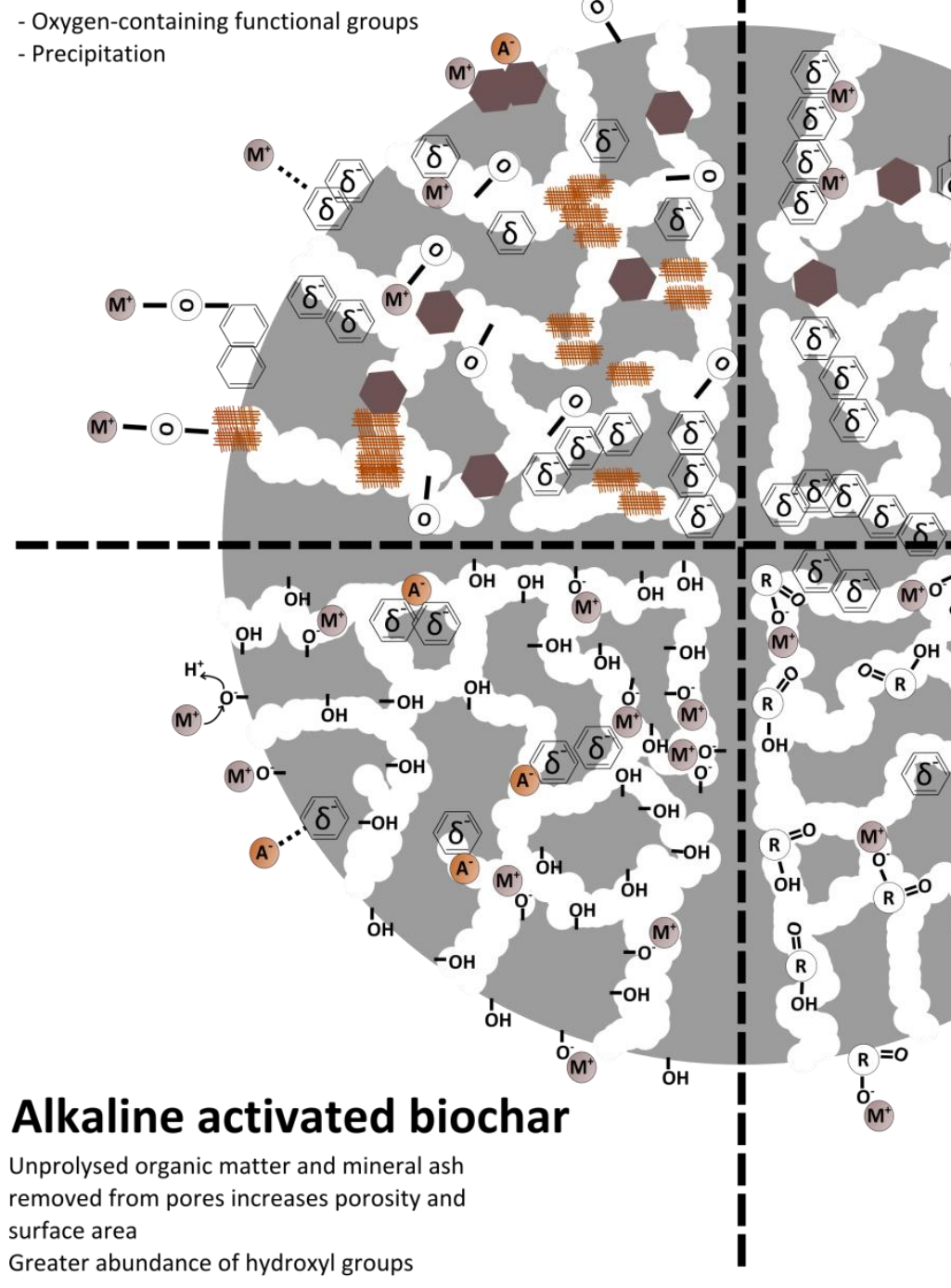

\section{Steam activated biochar}

Unprolysed organic matter removed from pores increases porosity and surface area Greater armaticity and fewer oxygenated functional groups
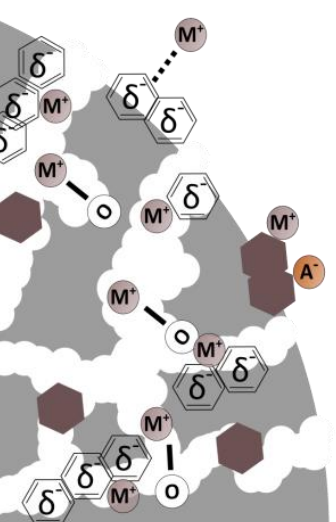

$$
\text { Acid or oxidising agent }
$$

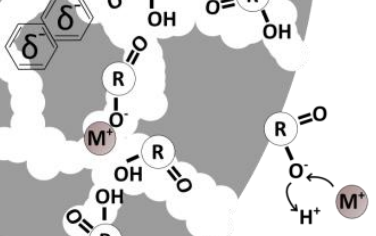

\section{Acid or oxidising agent}

I

- Oxygen-containing -он Hydroxyl group

I functional group

$\stackrel{\text { OH }}{1}=0$ Carboxyl group
Unpyrolysed organic matter

Unprolysed organic matter and mineral ash removed from pores increases porosity and surface area

Greater abundance of carboxyl groups

$\langle\underline{\delta}\rangle$ Polarised aromatic

Mineral/ash

Figure 3. Conceptual model identifying the mechanisms of metal cation (e.g. $\mathrm{Cd}^{2+}$, $\mathrm{Cu}^{2+}, \mathrm{Hg}^{2+}, \mathrm{Pb}^{2+}, \mathrm{Zn}^{2+}$ ) and oxyanion (e.g. $\mathrm{PO}_{4}{ }^{3-}, \mathrm{AsO}_{4}{ }^{3-}$ ) sorption to unactivated biochar and biochar physically activated with steam or chemically activated with acids, oxidising agents, or alkaline solutions 


\subsubsection{Chemical activation}

\subsubsection{Acids and oxidising agents}

293

294

295

296

297

298

299

300

301

302

303

304

305

306

307

308

309

310

311

312

313

314

315

Biochar surfaces contain several functional groups (e.g. carboxyl, hydroxyl, phenol) that can chemically bond with metal cations and remove them from solution. Acid treatments provide more oxygenated functional groups on biochar surfaces and increase the potential for biochar to chemically bind positively charged pollutants through specific adsorption. The modification of biochar by exposing the surface to acidic solutions forms carboxylic groups on the biochar surface (Hadjittofi et al., 2014; Qian et al., 2013) and develops micropores that lead to an increase in the surface area (Iriarte-Velasco et al., 2016).

Hadjittofi et al. (2014) activated a biochar derived from cactus fibres with $\mathrm{HNO}_{3}$ to increase the abundance of carboxylic groups on the surface since these groups act as strong $\mathrm{Cu}^{2+}$ binding sites. Adsorption was shown to be $\mathrm{pH}$ dependent since the sorption capacity of the resulting biochar was an order of magnitude greater at $\mathrm{pH} 6.5$, compared to $\mathrm{pH} 3$, indicating chemical sorption on oxygen-containing functional groups on the biochar surface. Oxygencontaining functional groups were also shown to be incorporated into structure of a rice straw biochar upon post-pyrolysis treatment with a mixture of $\mathrm{H}_{2} \mathrm{SO}_{4}$ and $\mathrm{HNO}_{3}$, evidenced by higher O/C ratios in the final product (Qian et al., 2013).

Acid-treatment increased the surface area, the total pore volume and volume of micropores after treatment of pine tree sawdust with diluted $\mathrm{H}_{3} \mathrm{PO}_{4}$ prior to pyrolysis (Zhao et al., 2017). The incorporation of $\mathrm{P}-\mathrm{O}-\mathrm{P}$ bonds into the $\mathrm{C}$ structure increased the $\mathrm{Pb}$ sorption capacity of the phosphoric acid-treated biochar by $>20 \%$ compared to a non-treated sample due to phosphate precipitation and surface adsorption (Zhao et al., 2017).

Activation of biochar with strong acids can be expensive at large scale and present environmental issues during the disposal of the activation media, so activation with $\mathrm{H}_{2} \mathrm{O}_{2}$, a less-expensive and cleaner product has been proposed as an alternative biochar activation 
medium to increase sorption capacity. Huff et al. (2016) reported an increase in oxygen-

317 containing functional groups in a pinewood biochar treated with $\mathrm{H}_{2} \mathrm{O}_{2}$. The cation exchange capacity of the biochar treated with $30 \% \mathrm{H}_{2} \mathrm{O}_{2}$ almost doubled that of an untreated biochar since the oxygen-containing functional groups in the surface of biochar, which were more abundant in the activated biochars, exchanged with cations in solution. Xue et al. (2012) found that treating a hydrochar with a $10 \% \mathrm{H}_{2} \mathrm{O}_{2}$ solution increased $\mathrm{Pb}$ sorption capacity compared to the unmodified hydrochar and attributed the increase to a greater abundance of carboxyl functional groups that can form complexes with Pb. Although Xue et al. (2012) observed similar mineral compositions in activated and unactivated biochars, the introduction of acid or oxidising agents dissolves mineral components from within the biochar structure and removes them from the biochar matrix. These minerals (e.g. P, $\mathrm{Ca}, \mathrm{Mg}, \mathrm{K}, \mathrm{Na}$ ) are particularly important for the removal of metal cations from water by some biochars due to precipitation (Xu et al., 2013), so some acid treatments may reduce sorption by precipitation.

\subsubsection{Alkaline solutions}

The most common alkali treatment of biochar is with Group I metal hydroxides (KOH or $\mathrm{NaOH})$. Activation of biochars with metal hydroxides increases adsorption by increasing porosity and surface area and by creating of a greater number of oxygenated functional groups on the surface of the biochar. These oxygenated functional groups provide proton donating exchange sites upon which metal cations such as $\mathrm{Pb}^{2+}$ chemically adsorb (Petrović et al., 2016). Goswami et al. (2016) demonstrated that activation of biochar with $\mathrm{KOH}$, followed by pyrolysing to $350-550{ }^{\circ} \mathrm{C}$ opened up the partially blocked pores and enlarged the diameters of smaller ones. The $\mathrm{KOH}$ and pyrolysis increased the surface area and increased adsorption of 338 Cd from aqueous solution by surface complexation. Hamid et al. (2014) provided further evidence that $\mathrm{Cu}$ sorption on $\mathrm{KOH}$ activated biochar was due to chemical adsorption, as the

340 kinetics of sorption fitted a pseudo second order model and thermodynamic studies indicated 
a spontaneous endothermic process. The increase in surface area resulting from modification

342 of biochar with $\mathrm{KOH}$ also increases the adsorption of oxyanions from solution. Jin et al.

343 (2014) also reported that maximum adsorption capacity of $\mathrm{As}(\mathrm{V})$ by biochar produced from

344 municipal solid wastes was increased 1.3 times from $24 \mathrm{mg} / \mathrm{g}$ to $31 \mathrm{mg} / \mathrm{g}$ after activation with $3452 \mathrm{M} \mathrm{KOH}$, due to an increase in surface area and the abundance of functional groups on the 346 biochar surface. Pietrzak et al. (2014) compared two activation methods using $\mathrm{NaOH}$, which 347 comprised either pre- or post-pyrolysis activation of feedstock or biochar by physical mixing 348 or by impregnation with a $\mathrm{NaOH}$ solution. The authors reported greater surface area and a 349 higher iodine sorption capacity when activation was conducted by physical mixing of both the 350 feedstock and the biochar with solid $\mathrm{NaOH}$.

\subsection{Biochar-based composites}

352 Biochar based composites are produced by impregnating biochar with metal oxides, clays, 353 organic compounds or carbonaceous materials, such as graphene oxide or carbon nanotubes, or by inoculation with microorganisms, to alter the surface properties of the biochar (Figure

4). Here the biochar is essentially used as a high-surface-area scaffold to support the materials being deposited. Composites are distinguished from chemical activation because they involve the creation of completely new functional groups on surfaces that did not previously exist on the biochar or feedstock surface.

\subsubsection{Metal oxides}

Biochars generally have a high surface area but a negative surface charge and high $\mathrm{pH}$. These properties make biochars excellent sorbents for metal cations due to specific adsorption on oxygenated functional groups, electrostatic attraction to aromatic groups and precipitation on 363 the mineral ash components of the biochar (Beesley et al., 2015), but poor sorbents for 364 oxyanion contaminants (e.g. $\mathrm{NO}_{3}{ }^{-}, \mathrm{PO}_{4}{ }^{3-}$ and $\mathrm{AsO}_{4}{ }^{3-}$ ). By exploiting the high surface area of biochars as a platform to embed a metal oxide with contrasting chemical properties (and 
usually a positive charge), biochar-based composites are capable of removing negatively

charged oxyanions from aqueous solutions. The objective of most methodologies to create

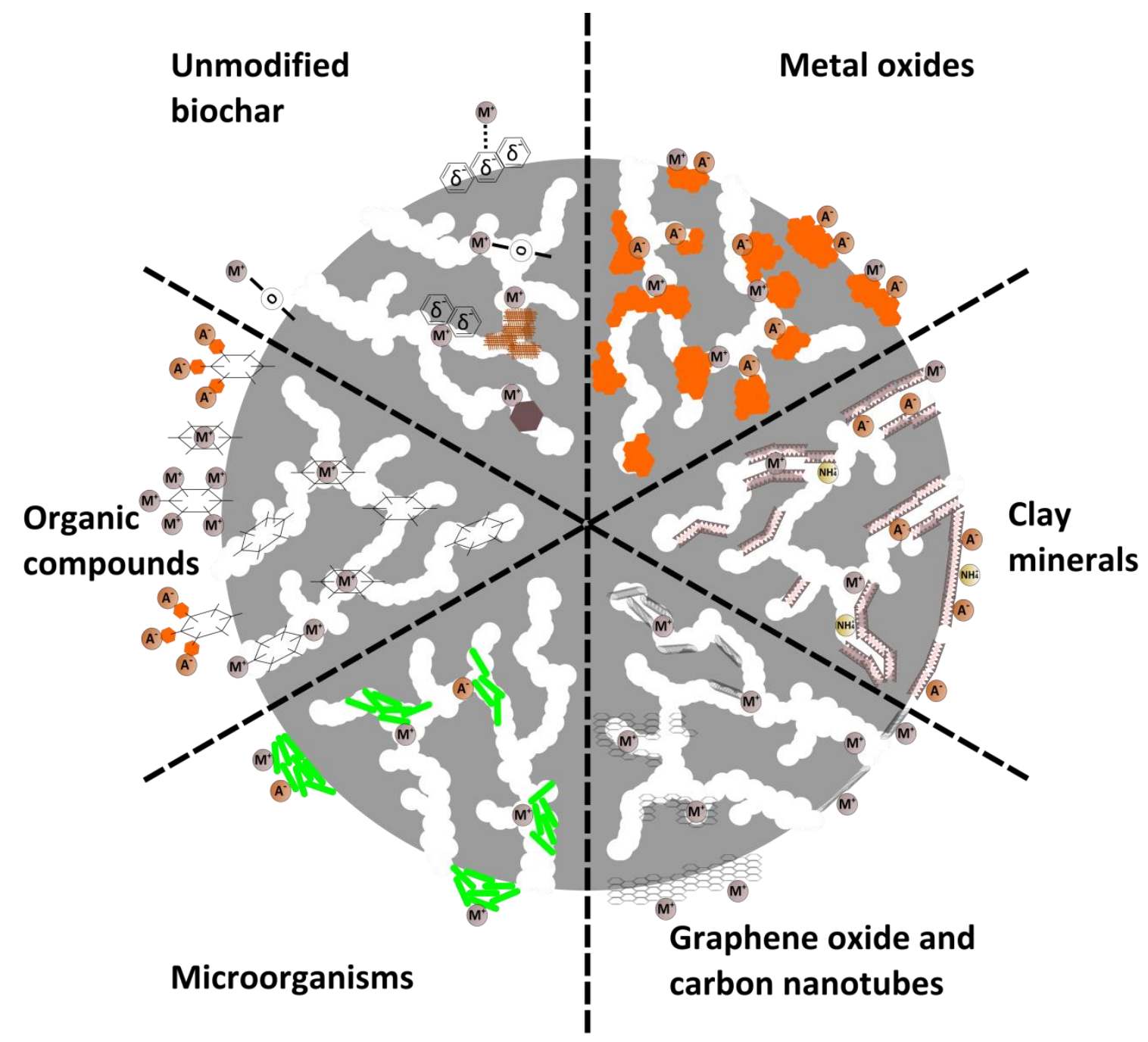
(A) Oxy-anion
(M) Metal cation
NHi) Polyatomic cation
Microorganism
I Oxygen-containing functional group
(6) Polarised aromatic structure

Unpyrolysed organic matter

- Carbon nanotube
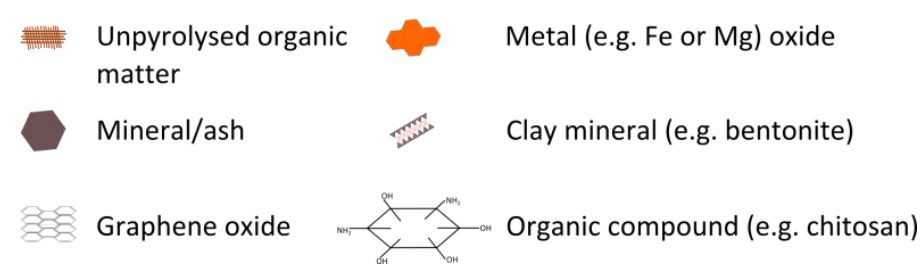

Figure 4. Conceptual model identifying the mechanisms of metal cation (e.g. $\mathrm{Cd}^{2+}$, $\mathrm{Cu}^{2+}, \mathrm{Hg}^{2+}, \mathrm{Pb}^{2+}, \mathrm{Zn}^{2+}$ ), oxyanion (e.g. $\mathrm{PO}_{4}{ }^{3-}, \mathrm{AsO}_{4}{ }^{3-}$ ) and polyatomic cation (e.g. $\mathrm{NH}_{4}{ }^{+}$) sorption to unmodified biochar and biochar modified with metal oxides, clay minerals, carbonaceous materials (graphene oxide and carbon nanotubes), microorganisms, and organic compounds. 
377 Generally, impregnation of biochar with metal oxides is performed by soaking biochars or

378 their feedstocks in solutions of metal nitrate or chloride salt solutions (Figure 5). The most

379 frequently used impregnation agents in the literature are $\mathrm{FeCl}_{3}, \mathrm{Fe}^{0}, \mathrm{Fe}\left(\mathrm{NO}_{3}\right)_{3}$ and $\mathrm{MgCl}_{2}$.

380 After soaking biochar with metal salt solutions, the biochar is heated under atmospheric 381 conditions (i.e. not low-oxygen conditions) at temperatures $50-300{ }^{\circ} \mathrm{C}$ to allow nitrates or 382 chlorides to be driven off as $\mathrm{NO}_{2}$ and $\mathrm{Cl}_{2}$ gases and convert the metal ions to metal oxides.

383 Agrafioti et al. (2014) demonstrated that soaking rice husk and municipal waste biomass 384 biochars in $\mathrm{CaO}$, iron powder and $\mathrm{FeCl}_{3}$ prior to pyrolysis created $\mathrm{Ca}, \mathrm{Fe}^{0}$ and $\mathrm{Fe}^{3+}$ modified 385 biochars, respectively. These modifications increased the capability of the biochars to remove $386 \mathrm{As}(\mathrm{V})$, but not $\mathrm{Cr}(\mathrm{VI})$, from aqueous solution. This observation is supported by Fristak et al. 387 (2017) who revealed a 20-fold increase in the sorption of As when corncob biochar was 388 modified with $\mathrm{Fe}\left(\mathrm{NO}_{3}\right)_{3}$ after pyrolysis, but that the modification had negligible effect on 389 sorption of the cationic lanthanide Eu.

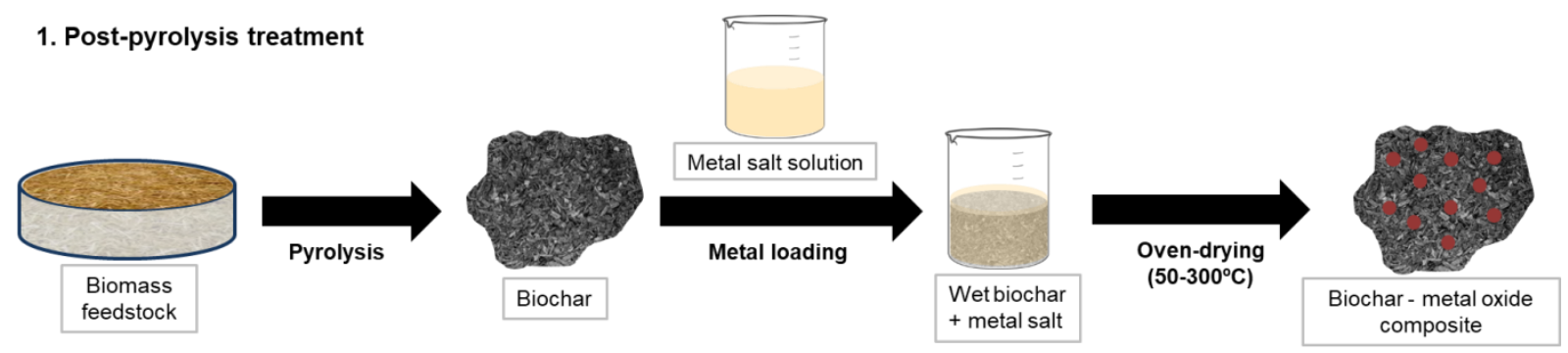

2. Pre-pyrolysis treatment
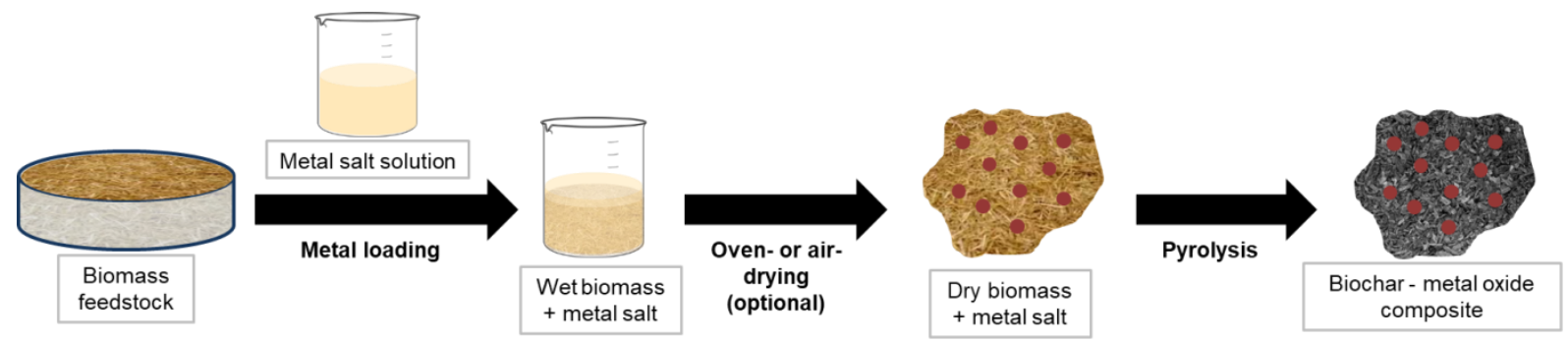
Most metal oxide modifications result in a reduction in the surface area of the biochar due to 395 clogging of pores with metal oxide precipitates (Rajapaksha et al., 2016; Zhou et al., 2017a). 396 Micháleková-Richveisová et al. (2017) used the same method as Fristak et al. (2017) to 397 modify biochars made from garden wood waste and wood chips as well as corncob, which 398 resulted in a decrease in the surface area of the biochar due to the filling of micro- and 399 mesopores with $\mathrm{Fe}$. However, despite the lower surface area, modification increased $\mathrm{PO}_{4}{ }^{3-}$ 400 sorption capacity by a factor of 12 to 50 due to $\mathrm{pH}$-dependent binding to positively charged 401 functional groups on the biochar surface.

402 Several attempts have been made to exploit the magnetic properties of Fe to create magnetic 403 biochars that are capable of removing both metal cation (Mohan et al., 2014) and oxyanion 404 pollutants (Zhou et al., 2014) from contaminated media. The magnetic property of modified 405 biochars enables the pollutant-loaded biochar to be removed from the media using a magnet. 406 Wang et al. (2015b) created a magnetic biochar by pyrolysing pinewood biomass with 407 hematite, a natural iron-oxide mineral, resulting in an As sorption capacity almost double that 408 of the unmodified biochar. The modification of biochar to improve magnetic properties was 409 developed further by Zhou et al. (2017b) by coating with a magnetised gelatin. The authors 410 observed a 2.6 times increase in the maximum adsorption of As(V) from solution after 411 biochar modification, attributed to the high electrostatic affinity of As(V) to iron-oxide particles and protonated oxygen-containing functional groups present on the biochar surface.

413 Biochar-based composites have also been produced by embedding oxides of $\mathrm{Al}, \mathrm{Mn}$ and $\mathrm{Mg}$ 414 on biochars and improving the sorption of both oxyanions (primarily As and P) and metal 415 cations (particularly $\mathrm{Pb}$ ). Zhang and Gao (2013) produced a biochar with high adsorption 416 capacity for $\mathrm{As}$ and $\mathrm{P}$ from solution by modification with $\mathrm{AlCl}_{3}$ to create a biochar-AlOOH nanocomposite, Wang et al. (2015a) modified biochar using $\mathrm{MnCl}_{2}$ and found that, compared 418 to the control, the manganese oxide-modified biochar displayed significantly improved 
sorption capacitiy for $\mathrm{As}$ and $\mathrm{Pb}$. Zhang et al. (2012) compared the modification of biochar produced from 5 different feedstocks by soaking the biochar in $\mathrm{MgCl}_{2}$ and applying further thermal treatment at $600^{\circ} \mathrm{C}$. The $\mathrm{MgO}$ content in the modified biochars ranged from $8.3 \%$ to $26.1 \%$, and the increased adsorption capacity for $\mathrm{PO}_{4}{ }^{3-}$ and $\mathrm{NO}_{3}{ }^{-}$was attributed to the positive charge of the $\mathrm{MgO}$ that precipitated on the biochar surfaces. The potential of $\mathrm{Mg}$-modification to increase the adsorption potential of biochar for metal cations was further explored by Jellali et al. (2016), who compared the adsorption of lead from solution by a biochar treated with $\mathrm{MgCl}_{2}$ prior to pyrolysis to that of unpyrolysed cypress sawdust. The maximum adsorption capacity of the Mg-modified biochar was approximately 7.4 times higher than that of the sawdust.

Generally the sorption of oxyanions $\left(\mathrm{PO}_{4}{ }^{3-}\right.$ and $\left.\mathrm{AsO}_{4}{ }^{3-}\right)$ on the surface of metal oxide biocharbased composites is due to chemical adsorption or electrostatic attraction to the positively charged metal oxide embedded on the surface (Ren et al., 2015; Zhou et al., 2014), whereas sorption of cationic metals is due to chemical adsorption on oxygenated functional groups on parts of the biochar that remain unmodified (Tan et al., 2015), or co-precipitation within the metal oxide lattice (Zhou et al., 2017a).

\subsubsection{Modification of living feedstock biomass}

Yao et al. (2013) demonstrated an innovative method of biochar modification by irrigating tomato plants with $\mathrm{Mg}$ solution and subsequently pyrolysing the biomass to yield a Mg-rich biochar with an improved adsorption capacity for $\mathrm{PO}_{4}{ }^{3-}$, compared to the control. The results showed a strong correlation between the removal rate of $\mathrm{P}$ and the concentration of $\mathrm{Mg}$ in the biochar. While interesting, this modification methodology is time consuming, and may be prohibitively expensive. 
443 The efficiency and homogeneity of metal oxide deposition on the surface of biochar can be 444 improved by using an electric field to evenly deposit metal ions from the electrodes and the 445 electrolyte on the surface of the biochar. The application of an electrical field, using an Al 446 electrode to a solution containing a $\mathrm{NaCl}$ electrolyte deposited nano-sized aluminium crystals 447 of beochemite $(\mathrm{AlOOH})$ on the surface of a marine macroalgae feedstock prior to pyrolysis 448 (Jung et al., 2015a). The resulting electro-modified biochar had a 45 times greater surface 449 area, and a well developed microporous structure, most likely due to the generation of strong 450 oxidising agents $\left(\mathrm{HOCl}\right.$ and $\left.\mathrm{OCl}^{-}\right)$from the $\mathrm{NaCl}$ electrolyte. Maximum $\mathrm{PO}_{4}{ }^{3-}$ sorption 451 capacity trebled, compared to the unmodified biochar. The optimum preparation parameters 452 were later identified for this electro-modification method as a current density of $39 \mathrm{~mA} / \mathrm{cm}^{2}$, a 453 pyrolysis temperature of $584 \mathrm{C}^{\circ}$, at a heating rate of $6.91{ }^{\circ} \mathrm{C} / \mathrm{min}$ (Jung et al., 2016a). Electromodification was further exploited by Jung et al. (2015b) to prepare $\mathrm{Mg} / \mathrm{Al}$-biochar based nanocomposites by using an $\mathrm{Al}$ electrode and $\mathrm{MgCl}_{2}$ as an electrolyte, which increased the $\mathrm{PO}_{4}{ }^{3-}$ sorption capacity by a factor of $\sim 28$, compared to the previous paper. The use of electro457 modification not only results in a more homogenous distribution of metal oxides over the 458 surface of the biochar, but also considerably decreases the time required to create metal oxide biochar based composites from a few hours to a few minutes.

\subsubsection{Clay minerals}

Impregnation of biochars with clay minerals, such as kaolinite, montmorillonite or bentonite, can modify biochar composition and physical properties, resulting in enhanced sorption capacity for oxyanions (e.g. $\mathrm{PO}_{4}{ }^{3-}$ ) and polyatomic cations (e.g. $\mathrm{NH}_{4}{ }^{+}$). To prepare clay mineral biochar-based composites, the feedstock is generally mixed with a suspension of the clay mineral prior to pyrolysis (Chen et al., 2017; Ismadji et al., 2016; Rawal et al., 2016; Yao 
mixed with iron sulphate resulted in the incorporation of mineral phases into the biochar

468 structure, revealed by high contents of $\mathrm{Al}, \mathrm{Fe}$ and $\mathrm{S}$ in the modified biochar (Rawal et al., 469 2016). Similarly, Yao et al. (2014) reported increased contents of $\mathrm{Al}, \mathrm{Fe}$ and $\mathrm{Na}$ in 470 montmorillonite and kaolinite biochar composites produced from plant biomass feedstocks 471 (bamboo, bagasse and hickory chips), indicating successful incorporation of both clay 472 minerals into the biochar structure. X-ray diffraction analysis of a bentonite biochar-based 473 composite produced by pyrolysis of cassava peel and bentonite revealed the typical basal spacing of the crystalline structure of the bentonite along with the amorphous structure of the biochar, indicating that bentonite structure remained after pyrolysis (Ismadji et al., 2016).

Chen et al. (2017) observed that mixing bamboo powder with montmorillonite prior to 477 pyrolysis increased the surface area and the pore volume and diameter, partly due to the 478 presence of layered montmorillonite. Layered surfaces have been observed by Scanning 479 Electron Microscope imaging of clay modified biochar, resembling common clay structure morphology (Yao et al., 2014). However, high pyrolysis temperatures can lead to loss of 48 structural water from the clay mineral, reducing the interlayer space of montmorillonite and 482 ultimately reducing the pore diameter and volume of the modified biochar (Chen et al., 2017; 483 Ismadji et al., 2016; Rawal et al., 2016).

484 The increased surface area of a montmorillonite modified biochar resulted in a greater 485 adsorption capacity for $\mathrm{NH}_{4}{ }^{+}$and $\mathrm{PO}_{4}{ }^{3-}$, compared to an unmodified biochar, but showed a stronger affinity for $\mathrm{PO}_{4}{ }^{3-}$ than for $\mathrm{NH}_{4}{ }^{+}$(Chen et al., 2017). $\mathrm{NH}_{4}{ }^{+}$was mainly controlled by 487 Van der Waals forces and partially by cation exchange, whereas phosphate was adsorbed 488 through electrostatic interaction and ionic bonding between $\mathrm{PO}_{4}{ }^{3-}$ and cations present in the 489 montmorillonite (Chen et al., 2017). The maximum adsorption capacity was $12.5 \mathrm{mg} / \mathrm{g}$ for $490 \mathrm{NH}_{4}{ }^{+}$and $105 \mathrm{mg} / \mathrm{g}$ for $\mathrm{PO}_{4}{ }^{3-}$ and slow-release behaviours were exhibited for both these 
nutrients, indicating a potential market for the saturated biochar-composite as a slow-release

492 fertiliser.

493 A bentonite-biochar composite produced from cassava peel and activated with $\mathrm{CO}_{2}$ at the

494 final pyrolysis stage, presented $\sim 150 \%$ greater sorption capacity for $\mathrm{NH}_{4}{ }^{+}$than an unmodified

495 biochar (Ismadji et al., 2016). This increase is ascribed to enhanced physical adsorption of $496 \mathrm{NH}_{4}^{+}$onto the surface of bentonite-biochar composite, together with its exchange with cations 497 present in the interlayer of bentonite and a more developed microporosity due to activation 498 with $\mathrm{CO}_{2}$.

499 Deposition of MgAl-layered double hydroxides (LDH), as anionic clay minerals, within the 500 biochar matrix increased the $\mathrm{PO}_{4}{ }^{3-}$ sorption capacity of the resulting biochar-based composite 501 with respect to unmodified biochars and other LDHs used as adsorbents. The enhanced 502 phosphate adsorption was due to successful deposition and separation of the LDH nanosized 503 particles on the biochar surface and increased sorption capacity either through anion exchange 504 or surface adsorption (Zhang et al., 2013b).

\subsubsection{Coating with carbonaceous materials (graphene oxide and carbon nanotubes)}

Graphene oxide is a widely used precursor for the production of graphene and has shown great sorption capacity for metals, such as $\mathrm{Cd}^{2+}, \mathrm{Co}^{2+}, \mathrm{Cu}^{2+}, \mathrm{Pb}^{2+}$ and $\mathrm{Zn}^{2+}$, which chemically bind with the oxygen-containing groups present on the graphene oxide surface (Ren et al., 2012; Sitko et al., 2013; Zhao et al., 2011). Graphene oxide-biochar composites have been used to improve biochar sorption capacity (Shang et al., 2016; Tang et al., 2015). These

511 composites are prepared by impregnation of the feedstock in a graphene oxide suspension 512 before pyrolysis, which generally increases the surface area and creates more oxygen513 containing functional groups than the unmodified biochar due to the incorporation of the 514 graphene structure in the composite after pyrolysis (Shang et al., 2016; Tang et al., 2015). 
515 Shang et al. (2016) found that $\mathrm{Cr}(\mathrm{VI})$ removal efficiency from aqueous solution by graphene

516 oxide biochar-based composite prepared from hyacinth biomass was considerably higher than 517 that of an unmodified biochar. The authors suggested that $\operatorname{Cr}(\mathrm{VI})$ sorption onto the composite 518 was likely via electrostatic attraction of $\mathrm{Cr}(\mathrm{VI})$ coupled with $\mathrm{Cr}(\mathrm{VI})$ reduction to $\mathrm{Cr}(\mathrm{III})$ and 519 Cr(III) complexation (Shang et al., 2016). Tang et al. (2015) mixed wheat straw with a 520 suspension of graphene oxide at different biomass:graphene oxide ratios $(0.1 \%, 0.5 \%$ and $5211 \%$ ) prior to slow pyrolysis at $600{ }^{\circ} \mathrm{C}$ and studied the graphene oxide-biochar composite 522 sorption characteristics for $\mathrm{Hg}^{2+}$ in aqueous solution. The $\mathrm{Hg}^{2+}$ removal efficiency increased with increasing the proportions of graphene oxide in the composite, with the highest load of 524 graphene oxide (1\%) removing $8.7 \%$ more $\mathrm{Hg}^{2+}$ from solution than the unmodified biochar. 525 Fourier transform infrared spectroscopy indicated that mercury was primarily bound by 526 oxygen-containing functional groups on the graphene oxide-biochar composite.

527 Biochar coated with carbon nanotubes (CNT) has been also synthesized and evaluated for its 528 metal cation sorption capacity (Inyang et al., 2014; Inyang et al., 2015). For the CNT-biochar 529 composites preparation, the biomass feedstock (sugarcane bagasse or hickory chips) was 530 mixed with a CNT suspension, stirred, and oven-dried prior to pyrolysis. CNT were 531 successfully incorporated to the biochar structure, resulting in higher surface area and pore 532 volume and increasingly negatively charged surface with increasing CNT loading (Inyang et 533 al., 2014). Improvement of $\mathrm{Pb}^{2+}$ sorption capacity with the CNT coating treatment was only 534 observed when hickory was used as a feedstock, whereas no effect was found for the 535 sugarcane biochar (Inyang et al., 2015). However, mixing the CNT with a surfactant (sodium 536 dodecyl benzene sulfonate) prior to biomass impregnation improved the $\mathrm{Pb}^{2+}$ removal 537 efficiency of both CNT-biochar composites (Inyang et al., 2015). $\mathrm{Pb}^{2+}$ was likely adsorbed 538 through interaction (chemical binding or electrostatic attraction) with oxygen-containing 539 groups in CNT-biochar composite surface (Inyang et al., 2015). 


\subsubsection{Microorganisms}

541 Biochar provides a high surface area inert material to support the colonisation and growth of

542 biofilms with desirable properties. The inoculation of microorganisms onto the surface of 543 biochars has primarily been attempted to facilitate the biodegradation of organic 544 contaminants, which is beyond the scope of this review. However, alongside biodegradation 545 of naphthenic acids, Frankel et al. (2016) observed biosorption of metals from solution by 546 biofilms on biochars colonised by microorganisms isolated from oil sands process water. 547 Sorption of $\mathrm{P}$ and As was up to 6 and 7 times greater than uncolonised biochar, respectively, 548 and up to 4 or 5 times greater than colonised and sterilised biochar.

\subsubsection{Organic compounds}

550 Biochars can be modified post-pyrolysis with organic compounds with functional groups that 551 are capable of creating strong bonds with both the surface of the biochar and also pollutants 552 from solution. Incorporation of amino groups onto the surface of biochar can enhance the 553 pollutant sorption capacity by inducing strong complexation with the amino moieties. This 554 modification can be achieved either by simple chemical reactions (Yang \& Jiang, 2014) or by 555 mixing biochars with polymers rich in amino groups, such as polyethylenimine or chitosan 556 (Ma et al., 2014; Zhang et al., 2015; Zhou et al., 2014; Zhou et al., 2013).

557 Yang and Jiang (2014) prepared an amino-modified biochar with a commercial saw dust 558 biochar by nitrification through electrophilic substitution reaction, using $\mathrm{HNO}_{3}$ and $\mathrm{H}_{2} \mathrm{SO}_{4}$, 559 followed by reduction with $\mathrm{Na}_{2} \mathrm{~S}_{2} \mathrm{O}_{4}$. Although no significant differences in the physical 560 structure were found between the modified and unmodified biochar, the surface of the 561 modified biochar had more functional groups, especially those associated to the amino 562 moieties. The amino-modification resulted in 5 times greater $\mathrm{Cu}^{2+}$ sorption capacity which was 563 strongly complexed by the amino groups present on the modified biochar surface (Yang \& 564 Jiang, 2014). 
565 A rice-husk biochar, pre-treated with acid or alkali solutions, modified by mixing with 566 polyethylenimine (PEI)/methanol solution, had a greater abundance of functional groups on 567 its surface and was richer in $\mathrm{N}$ and $\mathrm{O}$, confirming the incorporation of PEI to the structure 568 (Ma et al., 2014). The presence of more amine functional groups enhanced the sorption 569 capacity of the modified biochar for $\mathrm{Cr}(\mathrm{VI})$, which was partially reduced to $\mathrm{Cr}$ (III) during 570 adsorption (Ma et al., 2014).

571 Zhou et al. (2013) prepared chitosan-biochar composites by mixing biochars produced from 572 bamboo, sugarcane bagasse, hickory wood and peanut hull feedstocks with an acid chitosan 573 solution. The composites had a smaller surface area than the unmodified biochars, probably 574 due to the pore blockage by the incorporation of chitosan in the biochar structure, which was 575 confirmed by higher N, H and O contents. Generally, modification with chitosan increased the 576 metal cation sorption capacity of biochars, although some exceptions were found probably 577 related to the lower surface area. $\mathrm{Pb}$ adsorption isotherms of chitosan modified bamboo 578 biochar and characterisation $\mathrm{Pb}$-laden composites suggested that $\mathrm{Pb}$ was adsorbed primarily 579 due to an interaction with amine functional groups of chitosan (Zhou et al., 2013).

580 Chitosan has been also applied to improve the impregnation of biochars with metal oxides to 581 produce magnetic biochars (Zhang et al., 2015; Zhou et al., 2014). When mixed with a $\gamma$ $582 \mathrm{Fe}_{2} \mathrm{O}_{3}$-biochar composite, more functional groups were incorporated into the chitosan- $\gamma$ $583 \mathrm{Fe}_{2} \mathrm{O}_{3}$-biochar composite, which showed promising results concerning $\mathrm{Cr}(\mathrm{VI})$ sorption from 584 aqueous solution (Zhang et al., 2015). Similarly, a modified biochar produced using bamboo 585 biochar, chitosan and zero valent iron (ZVI) particles at various ratios, showed much higher 586 removal efficiency for $\mathrm{Pb}^{+2}, \mathrm{Cr}(\mathrm{VI}), \mathrm{As}(\mathrm{V})$ and $\mathrm{P}$ than the unmodified biochar (Zhou et al., 587 2014). Coating biochar with chitosan alone (with no ZVI addition) enhanced the removal 588 efficiency of $\mathrm{Pb}^{+2}$ and $\mathrm{Cr}(\mathrm{VI})$ due to the complexation capacity of the amine functional groups 589 of chitosan, but the presence of ZVI further improved the removal of these metals. Whereas 
the chitosan-only modified $\mathrm{BC}$ showed no sorption capacity for $\mathrm{As}(\mathrm{V})$ and $\mathrm{P}$, the presence of

591 ZVI in the composite greatly increased the removal efficiency of $\mathrm{As}(\mathrm{V})$ and $\mathrm{P}$, likely adsorbed by electrostatic interactions with ZVI particles (Zhou et al., 2014).

\section{Future work}

594 Further development work will mainly optimise the choice of feedstock, pyrolysis 595 temperature, and conditions under which biochars are modified (e.g. temperature, rate, 596 concentration and choice of chemical compound, solid:solution ratio, mixing) in order to 597 obtain a versatile suite of enhanced biochars with highly predictable properties that can be 598 applied to multiple remediation scenarios. New developments should seek to find

599

600

601

602

603

604

605

606

607

608

609

610

compromises between the biochar feedstock, modification method and sorption performance that minimises costs and maximises the breadth of technical applicability, while maintaining long-term performance.

Biochar modification will inevitably raise the production costs, thus the profitability of using modified biochars compared to other materials, such as activated carbons, as adsorbents should be analysed for each specific case. The production and application costs of biochar as adsorbent for pollutants in aqueous solutions depends on multiple factors that present some uncertainties and can vary considerably. These include the origin and availability of the feedstock; preparation of the raw material (cleaning, drying); costs of biochar production, which will depend largely on pyrolysis conditions (slow vs fast, temperature); distribution costs; the environmental impact and lifetime and regeneration after use (Alhashimi \& Aktas, 2017). The economical assessment of using any adsorbent should also consider its efficiency for a given contaminant or material. Physical activation of biochar would increase the energy consumption costs, whereas chemical activation and production of biochar-based composites would also include the price of reagents (Banerjee et al., 2016). In these cases, a particularly challenging aspect of future optimisation is to decrease the quantity of chemicals required to 
615 activate or modify the biochar produced to minimise costs of production while maintaining

616 maximum sorption capacity by optimising the biochar:modifying agent ratio .

617 There is a considerable opportunity to develop biochars that act as scaffolds for nano-

618 adsorbents which have received increasing research attention recently (Kyzas \& Matis, 2015).

619 Creating biochar-based nano-adsorbents would offer a huge potential to develop adsorbent 620 nano-materials with a high surface area and a specific surface functionality while using as 621 little materials as possible.

622 The stability of biochar-based composite modifications over time should be monitored in 623 future experiments as some of the materials imbibed in the biochar matrix (e.g. metal 624 compounds, C nanotubes, organic compounds) can leach away from the biochar if they are 625 not well fixed. To address this issue, leaching tests are required. One scenario worthy of 626 investigation is the stability of metal-biochar composites in acidic solutions ( $\mathrm{pH} 4-5)$, to 627 determine whether metals are released from the biochar matrix.

628 Another gap is the ecotoxicology of these new biochar formulations. Biochar itself has been 629 shown to be good for environmental applications, but sometimes has been shown to contain 630 toxic compounds (Soudek et al., 2016). Modifying or activating the biochar leads to chemical 631 and physical changes that could potentially increase the toxicity (reactivity, presence of 632 nanoparticles, metals, etc). For example, Shim et al. (2015) pointed out that activated biochars 633 can induce toxicity to Daphnia magna. To ensure environmental protection, the toxicity of 634 modified biochars needs to be evaluated to avoid undesirable impacts to aquatic organisms 635 (Gonçalves et al., 2016).

636 Also important is the sustainability of modified biochars and how they may contribute to the 637 circular economy. A considerable challenge facing the designers of biochars and activated or 638 modified biochars is to enable the regeneration and re-use of the sorbent so that the 'pollutant' 
639 can be desorbed from the biochar surface and recovered. The biochar may then be used to

640 adsorb more pollutants from water. This is particularly important when considering disposal

641 of biochar after it has been used to remediate water. If the saturated biochar is considered

642 hazardous waste then disposal may be costly and so a re-usable sorbent offers environmental

643 and economic advantages. If the inorganic pollutant loaded on the biochar cannot be

644 efficiently desorbed and recovered then the saturated biochar may still be used as a resource.

645 For example, $\mathrm{P}$ and $\mathrm{N}$ saturated modified biochars could be of potential use in agriculture 646 (cropping) or ecological restoration (revegetation) as a slow release fertiliser when applied to 647 soils (Ismail \& Hameed, 2016; Roy, 2016). Accordingly, biochars containing Cu or Zn may 648 be useful as micronutrient fertilisers.

\section{Conclusions}

650 The development of methods to modify biochars to enhance their inorganic pollutant sorption 651 capacity or to expand the breadth pollutants that they can be removed from aqueous solution 652 is in its infancy. Physical and chemical activation of biochar can increase the surface area and 653 increase the abundance of oxygenated functional groups to increase cation adsorption. 654 Embedding materials on the surface of biochar can alter the properties of the surface by 655 creating biochar-based composites, enabling the adsorption of different pollutants. Research 656 into biochar-based composites have primarily been progressed by embedding iron or manganese oxides to increase oxyanion sorption capacity.

658 The E-supplement contains a table which classifies the inorganic contaminants of primary 659 concern classified by their chemical behavior and includes citations to peer reviewed articles 660 that identify their sources in water. 
662

This research did not receive any specific grant from funding agencies in the public, commercial, or not-for-profit sectors. However, EMJ and GA are thankful to the Cooperation Program UAM-Banco Santander, grant no. 2017/ASIA/07.

\section{References}

1. Agrafioti, E., Kalderis, D., Diamadopoulos, E. 2014. Ca and Fe modified biochars as adsorbents of arsenic and chromium in aqueous solutions. Journal of Environmental Management, 146, 444-450.

2. Ahmad, M., Lee, S.S., Dou, X., Mohan, D., Sung, J.-K., Yang, J.E., Ok, Y.S. 2012. Effects of pyrolysis temperature on soybean stover-and peanut shell-derived biochar properties and TCE adsorption in water. Bioresource technology, 118, 536-544.

3. Alhashimi, H.A., Aktas, C.B. 2017. Life cycle environmental and economic performance of biochar compared with activated carbon: A meta-analysis. Resources, Conservation and Recycling, 118, 13-26.

4. Banerjee, S., Mukherjee, S., LaminKa-ot, A., Joshi, S., Mandal, T., Halder, G. 2016. Biosorptive uptake of $\mathrm{Fe} 2+, \mathrm{Cu} 2+$ and $\mathrm{As} 5+$ by activated biochar derived from Colocasia esculenta: Isotherm, kinetics, thermodynamics, and cost estimation. Journal of advanced research, 7(5), 597-610.

5. Beesley, L., Moreno-Jimenez, E., Fellet, G., Carrijo, L., Sizmur, T. 2015. Biochar and heavy metals. in: Biochar for Environmental Management: Science and Technology, (Eds.) J. Lehmann, S. Joseph, Routledge. Abingdon, UK.

6. Cai, R., Wang, X., Ji, X., Peng, B., Tan, C., Huang, X. 2017. Phosphate reclaim from simulated and real eutrophic water by magnetic biochar derived from water hyacinth. Journal of Environmental Management, 187, 212-219.

7. Cantrell, K.B., Hunt, P.G., Uchimiya, M., Novak, J.M., Ro, K.S. 2012. Impact of pyrolysis temperature and manure source on physicochemical characteristics of biochar. Bioresource technology, 107, 419-428.

8. Cao, X., Ma, L., Gao, B., Harris, W. 2009. Dairy-manure derived biochar effectively sorbs lead and atrazine. Environmental science \& technology, 43(9), 3285-3291.

9. Chen, B., Chen, Z., Lv, S. 2011. A novel magnetic biochar efficiently sorbs organic pollutants and phosphate. Bioresource technology, 102(2), 716-723.

10. Chen, L., Chen, X.L., Zhou, C.H., Yang, H.M., Ji, S.F., Tong, D.S., Zhong, Z.K., Yu, W.H., Chu, M.Q. 2017. Environmental-friendly Montmorillonite-Biochar Composites: Facile Production and Tunable Adsorption-Release of Ammonium and Phosphate. Journal of Cleaner Production.

11. Chen, T., Zhang, Y., Wang, H., Lu, W., Zhou, Z., Zhang, Y., Ren, L. 2014. Influence of pyrolysis temperature on characteristics and heavy metal adsorptive performance of biochar derived from municipal sewage sludge. Bioresource technology, 164, 47-54. 
12. Conley, D.J., Paerl, H.W., Howarth, R.W., Boesch, D.F., Seitzinger, S.P., Havens, K.E., Lancelot, C., Likens, G.E. 2009. Controlling eutrophication: nitrogen and phosphorus. Science, 323(5917), 1014-1015.

13. Ding, W., Dong, X., Ime, I.M., Gao, B., Ma, L.Q. 2014. Pyrolytic temperatures impact lead sorption mechanisms by bagasse biochars. Chemosphere, 105, 68-74.

14. Dudgeon, D., Arthington, A.H., Gessner, M.O., Kawabata, Z.I., Knowler, D.J., Lévêque, C., Naiman, R.J., Prieur-Richard, A.H., Soto, D., Stiassny, M.L. 2006. Freshwater biodiversity: importance, threats, status and conservation challenges. Biological reviews, 81(2), 163-182.

15. Fletcher, A.J., Smith, M.A., Heinemeyer, A., Lord, R., Ennis, C.J., Hodgson, E.M., Farrar, K. 2014. Production factors controlling the physical characteristics of biochar derived from phytoremediation willow for agricultural applications. BioEnergy Research, 7(1), 371-380.

16. Frankel, M.L., Bhuiyan, T.I., Veksha, A., Demeter, M.A., Layzell, D.B., Helleur, R.J., Hill, J.M., Turner, R.J. 2016. Removal and biodegradation of naphthenic acids by biochar and attached environmental biofilms in the presence of co-contaminating metals. Bioresource technology, 216, 352-361.

17. Frišták, V., Micháleková-Richveisová, B., Víglašová, E., Ďuriška, L., Galamboš, M., Moreno-Jimenéz, E., Pipíška, M., Soja, G. 2017. Sorption separation of Eu and As from single-component systems by Fe-modified biochar: kinetic and equilibrium study. Journal of the Iranian Chemical Society, 14(3), 521-530.

18. Gomez-Eyles, J.L., Beesley, L., Moreno-Jimenez, E., Ghosh, U., Sizmur, T. 2013. The potential of biochar amendments to remediate contaminated soils. Biochar and Soil Biota, 4, 100-133.

19. Gonçalves, S.P.C., Strauss, M., Delite, F.S., Clemente, Z., Castro, V.L., Martinez, D.S.T. 2016. Activated carbon from pyrolysed sugarcane bagasse: Silver nanoparticle modification and ecotoxicity assessment. Science of The Total Environment, 565, 833840.

20. Goswami, R., Shim, J., Deka, S., Kumari, D., Kataki, R., Kumar, M. 2016. Characterization of cadmium removal from aqueous solution by biochar produced from Ipomoea fistulosa at different pyrolytic temperatures. Ecological Engineering, 97, 444451.

21. Hadjittofi, L., Prodromou, M., Pashalidis, I. 2014. Activated biochar derived from cactus fibres - Preparation, characterization and application on $\mathrm{Cu}$ (II) removal from aqueous solutions. Bioresource technology, 159, 460-464.

22. Hamid, S.B.A., Chowdhury, Z.Z., Zain, S.M. 2014. Base catalytic approach: A promising technique for the activation of biochar for equilibrium sorption studies of copper, $\mathrm{Cu}$ (II) ions in single solute system. Materials, 7(4), 2815-2832.

23. Harvey, O.R., Herbert, B.E., Rhue, R.D., Kuo, L.-J. 2011. Metal interactions at the biochar-water interface: energetics and structure-sorption relationships elucidated by flow adsorption microcalorimetry. Environmental science \& technology, 45(13), 55505556. 
24. Hu, X., Ding, Z., Zimmerman, A.R., Wang, S., Gao, B. 2015. Batch and column sorption of arsenic onto iron-impregnated biochar synthesized through hydrolysis. water research, 68, 206-216.

25. Huff, M.D., Lee, J.W. 2016. Biochar-surface oxygenation with hydrogen peroxide. Journal of Environmental Management, 165, 17-21.

26. Inyang, M., Gao, B., Zimmerman, A., Zhang, M., Chen, H. 2014. Synthesis, characterization, and dye sorption ability of carbon nanotube-biochar nanocomposites. Chemical Engineering Journal, 236, 39-46.

27. Inyang, M., Gao, B., Zimmerman, A., Zhou, Y., Cao, X. 2015. Sorption and cosorption of lead and sulfapyridine on carbon nanotube-modified biochars. Environmental Science and Pollution Research, 22(3), 1868-1876.

28. Iriarte-Velasco, U., Sierra, I., Zudaire, L., Ayastuy, J.L. 2016. Preparation of a porous biochar from the acid activation of pork bones. Food and Bioproducts Processing, 98, 341-353.

29. Ismadji, S., Tong, D.S., Soetaredjo, F.E., Ayucitra, A., Yu, W.H., Zhou, C.H. 2016. Bentonite hydrochar composite for removal of ammonium from Koi fish tank. Applied Clay Science, 119, 146-154.

30. Ismail, Z.Z., Hameed, B.B. 2016. Sustainable Application of Agro-industrial Biomass Waste for Water Treatment: Recycling of Sunflower Seeds Hulls for Ammonium Removal. The Journal of Solid Waste Technology and Management, 42(4), 251-259.

31. Jellali, S., Diamantopoulos, E., Haddad, K., Anane, M., Durner, W., Mlayah, A. 2016. Lead removal from aqueous solutions by raw sawdust and magnesium pretreated biochar: Experimental investigations and numerical modelling. Journal of Environmental Management, 180, 439-449.

32. Jin, H., Capareda, S., Chang, Z., Gao, J., Xu, Y., Zhang, J. 2014. Biochar pyrolytically produced from municipal solid wastes for aqueous As (V) removal: Adsorption property and its improvement with $\mathrm{KOH}$ activation. Bioresource technology, 169, 622-629.

33. Jung, K.-W., Hwang, M.-J., Jeong, T.-U., Ahn, K.-H. 2015a. A novel approach for preparation of modified-biochar derived from marine macroalgae: Dual purpose electromodification for improvement of surface area and metal impregnation. Bioresource technology, 191, 342-345.

34. Jung, K.-W., Jeong, T.-U., Hwang, M.-J., Kim, K., Ahn, K.-H. 2015b. Phosphate adsorption ability of biochar $/ \mathrm{Mg}-\mathrm{Al}$ assembled nanocomposites prepared by aluminumelectrode based electro-assisted modification method with $\mathrm{MgCl} 2$ as electrolyte. Bioresource technology, 198, 603-610.

35. Jung, K.-W., Jeong, T.-U., Kang, H.-J., Chang, J.-S., Ahn, K.-H. 2016a. Preparation of modified-biochar from Laminaria japonica: Simultaneous optimization of aluminum electrode-based electro-modification and pyrolysis processes and its application for phosphate removal. Bioresource technology, 214, 548-557.

36. Jung, K.-W., Kim, K., Jeong, T.-U., Ahn, K.-H. 2016b. Influence of pyrolysis temperature on characteristics and phosphate adsorption capability of biochar derived from waste-marine macroalgae (Undaria pinnatifida roots). Bioresource technology, 200, 1024-1028. 
37. Kim, K.H., Kim, J.-Y., Cho, T.-S., Choi, J.W. 2012. Influence of pyrolysis temperature on physicochemical properties of biochar obtained from the fast pyrolysis of pitch pine (Pinus rigida). Bioresource technology, 118, 158-162.

38. Kim, W.-K., Shim, T., Kim, Y.-S., Hyun, S., Ryu, C., Park, Y.-K., Jung, J. 2013. Characterization of cadmium removal from aqueous solution by biochar produced from a giant Miscanthus at different pyrolytic temperatures. Bioresource technology, 138, 266270 .

39. Kotaś, J., Stasicka, Z. 2000. Chromium occurrence in the environment and methods of its speciation. Environmental Pollution, 107(3), 263-283.

40. Kyzas, G.Z., Matis, K.A. 2015. Nanoadsorbents for pollutants removal: a review. Journal of Molecular Liquids, 203, 159-168.

41. Lee, J.W., Kidder, M., Evans, B.R., Paik, S., Buchanan Iii, A., Garten, C.T., Brown, R.C. 2010. Characterization of biochars produced from cornstovers for soil amendment. Environmental Science \& Technology, 44(20), 7970-7974.

42. Liang, B., Lehmann, J., Solomon, D., Kinyangi, J., Grossman, J., O'neill, B., Skjemstad, J., Thies, J., Luizao, F., Petersen, J. 2006. Black carbon increases cation exchange capacity in soils. Soil Science Society of America Journal, 70(5), 1719-1730.

43. Lima, I.M., Marshall, W.E. 2005. Adsorption of selected environmentally important metals by poultry manure-based granular activated carbons. Journal of Chemical Technology and Biotechnology, 80(9), 1054-1061.

44. Liu, S.-b., Tan, X.-f., Liu, Y.-g., Gu, Y.-l., Zeng, G.-m., Hu, X.-j., Wang, H., Zhou, L., Jiang, L.-h., Zhao, B.-b. 2016. Production of biochars from Ca impregnated ramie biomass (Boehmeria nivea (L.) Gaud.) and their phosphate removal potential. RSC Advances, 6(7), 5871-5880.

45. Lou, K., Rajapaksha, A.U., Ok, Y.S., Chang, S.X. 2016. Pyrolysis temperature and steam activation effects on sorption of phosphate on pine sawdust biochars in aqueous solutions. Chemical Speciation \& Bioavailability, 28(1-4), 42-50.

46. Ma, Y., Liu, W.-J., Zhang, N., Li, Y.-S., Jiang, H., Sheng, G.-P. 2014. Polyethylenimine modified biochar adsorbent for hexavalent chromium removal from the aqueous solution. Bioresource technology, 169, 403-408.

47. Micháleková-Richveisová, B., Frišták, V., Pipíška, M., Ďuriška, L., Moreno-Jimenez, E., Soja, G. 2017. Iron-impregnated biochars as effective phosphate sorption materials. Environmental Science and Pollution Research, 24(1), 463-475.

48. Mohan, D., Kumar, H., Sarswat, A., Alexandre-Franco, M., Pittman Jr, C.U. 2014. Cadmium and lead remediation using magnetic oak wood and oak bark fast pyrolysis bio-chars. Chemical Engineering Journal, 236, 513-528.

49. Moore, J.W., Ramamoorthy, S. 2012. Heavy metals in natural waters: applied monitoring and impact assessment. Springer Science \& Business Media.

50. Mueller, D.K., Helsel, D.R. 1996. Nutrients in the nation's waters: too much of a good thing?

51. Mukherjee, A., Zimmerman, A.R., Harris, W. 2011. Surface chemistry variations among a series of laboratory-produced biochars. Geoderma, 163(3-4), 247-255. 
827 52. Niu, Q., Luo, J., Xia, Y., Sun, S., Chen, Q. 2017. Surface modification of bio-char by dielectric barrier discharge plasma for $\mathrm{Hg} 0$ removal. Fuel Processing Technology, 156, 310-316.

53. Paethanom, A., Yoshikawa, K. 2012. Influence of pyrolysis temperature on rice husk char characteristics and its tar adsorption capability. Energies, 5(12), 4941-4951.

54. Petrović, J.T., Stojanović, M.D., Milojković, J.V., Petrović, M.S., Šoštarić, T.D., Laušević, M.D., Mihajlović, M.L. 2016. Alkali modified hydrochar of grape pomace as a perspective adsorbent of $\mathrm{Pb} 2+$ from aqueous solution. Journal of Environmental Management, 182, 292-300.

55. Pietrzak, R., Nowicki, P., Kaźmierczak, J., Kuszyńska, I., Goscianska, J., Przepiórski, J. 2014. Comparison of the effects of different chemical activation methods on properties of carbonaceous adsorbents obtained from cherry stones. Chemical Engineering Research and Design, 92(6), 1187-1191.

56. Qian, K., Kumar, A., Patil, K., Bellmer, D., Wang, D., Yuan, W., Huhnke, R.L. 2013. Effects of biomass feedstocks and gasification conditions on the physiochemical properties of char. Energies, 6(8), 3972-3986.

57. Qian, L., Zhang, W., Yan, J., Han, L., Chen, Y., Ouyang, D., Chen, M. 2017. Nanoscale zero-valent iron supported by biochars produced at different temperatures: Synthesis mechanism and effect on Cr(VI) removal. Environmental Pollution, 223, 153-160.

58. Rajapaksha, A.U., Chen, S.S., Tsang, D.C., Zhang, M., Vithanage, M., Mandal, S., Gao, B., Bolan, N.S., Ok, Y.S. 2016. Engineered/designer biochar for contaminant removal/immobilization from soil and water: potential and implication of biochar modification. Chemosphere, 148(27), 6e291.

59. Rawal, A., Joseph, S.D., Hook, J.M., Chia, C.H., Munroe, P.R., Donne, S., Lin, Y., Phelan, D., Mitchell, D.R., Pace, B. 2016. Mineral-Biochar Composites: Molecular Structure and Porosity. Environmental science \& technology, 50(14), 7706-7714.

60. Ren, J., Li, N., Li, L., An, J.-K., Zhao, L., Ren, N.-Q. 2015. Granulation and ferric oxides loading enable biochar derived from cotton stalk to remove phosphate from water. Bioresource Technology, 178, 119-125.

61. Ren, Y., Yan, N., Feng, J., Ma, J., Wen, Q., Li, N., Dong, Q. 2012. Adsorption mechanism of copper and lead ions onto graphene nanosheet $/ \delta$-MnO 2. Materials Chemistry and Physics, 136(2), 538-544.

62. Roy, E.D. 2016. Phosphorus recovery and recycling with ecological engineering: A review. Ecological Engineering, 98, 213-227.

63. Shang, M.-r., Liu, Y.-g., Liu, S.-b., Zeng, G.-m., Tan, X.-f., Jiang, L.-h., Huang, X.-X., Ding, Y., Guo, Y.-m., Wang, S.-f. 2016. A novel graphene oxide coated biochar composite: synthesis, characterization and application for $\mathrm{Cr}$ (VI) removal. $R S C$ Advances, 6(88), 85202-85212.

64. Shannon, M.A., Bohn, P.W., Elimelech, M., Georgiadis, J.G., Marinas, B.J., Mayes, A.M. 2008. Science and technology for water purification in the coming decades. Nature, 452(7185), 301-310. 
65. Shim, T., Yoo, J., Ryu, C., Park, Y.-K., Jung, J. 2015. Effect of steam activation of biochar produced from a giant Miscanthus on copper sorption and toxicity. Bioresource technology, 197, 85-90.

66. Sitko, R., Turek, E., Zawisza, B., Malicka, E., Talik, E., Heimann, J., Gagor, A., Feist, B., Wrzalik, R. 2013. Adsorption of divalent metal ions from aqueous solutions using graphene oxide. Dalton Transactions, 42(16), 5682-5689.

67. Sizmur, T., Quilliam, R., Puga, A.P., Moreno-Jiménez, E., Beesley, L., Gomez-Eyles, J.L. 2016. Application of biochar for soil remediation. Agricultural and Environmental Applications of Biochar: Advances and Barriers(sssaspecpub63), 295-324.

68. Song, Z., Lian, F., Yu, Z., Zhu, L., Xing, B., Qiu, W. 2014. Synthesis and characterization of a novel MnOx-loaded biochar and its adsorption properties for $\mathrm{Cu} 2+$ in aqueous solution. Chemical Engineering Journal, 242, 36-42.

69. Soudek, P., Valseca, I.R., Petrová, Š., Song, J., Vaněk, T. 2016. Characteristics of different types of biochar and effects on the toxicity of heavy metals to germinating sorghum seeds. Journal of Geochemical Exploration.

70. Tan, X., Liu, Y., Zeng, G., Wang, X., Hu, X., Gu, Y., Yang, Z. 2015. Application of biochar for the removal of pollutants from aqueous solutions. Chemosphere, 125, 70-85.

71. Tang, J., Lv, H., Gong, Y., Huang, Y. 2015. Preparation and characterization of a novel graphene/biochar composite for aqueous phenanthrene and mercury removal. Bioresource technology, 196, 355-363.

72. Trakal, L., Veselská, V., Šafařík, I., Vítková, M., Č́́halová, S., Komárek, M. 2016. Lead and cadmium sorption mechanisms on magnetically modified biochars. Bioresource technology, 203, 318-324.

73. Tripathi, M., Sahu, J., Ganesan, P. 2016. Effect of process parameters on production of biochar from biomass waste through pyrolysis: A review. Renewable and Sustainable Energy Reviews, 55, 467-481.

74. Uchimiya, M., Lima, I.M., Thomas Klasson, K., Chang, S., Wartelle, L.H., Rodgers, J.E. 2010. Immobilization of heavy metal ions (CuII, CdII, NiII, and PbII) by broiler litterderived biochars in water and soil. Journal of Agricultural and Food Chemistry, 58(9), 5538-5544.

75. Vu, T.M., Doan, D.P., Van, H.T., Nguyen, T.V., Vigneswaran, S., Ngo, H.H. 2017. Removing ammonium from water using modified corncob-biochar. Science of The Total Environment, 579, 612-619.

76. Wang, H., Tian, Z., Jiang, L., Luo, W., Wei, Z., Li, S., Cui, J., Wei, W. 2017a. Highly efficient adsorption of $\mathrm{Cr}$ (VI) from aqueous solution by Fe3+ impregnated biochar. Journal of Dispersion Science and Technology, 38(6), 815-825.

77. Wang, S.-y., Tang, Y.-k., Li, K., Mo, Y.-y., Li, H.-f., Gu, Z.-q. 2014. Combined performance of biochar sorption and magnetic separation processes for treatment of chromium-contained electroplating wastewater. Bioresource technology, 174, 67-73.

78. Wang, S., Gao, B., Li, Y. 2016. Enhanced arsenic removal by biochar modified with nickel (Ni) and manganese (Mn) oxyhydroxides. Journal of Industrial and Engineering Chemistry, 37, 361-365. 
79. Wang, S., Gao, B., Li, Y., Creamer, A.E., He, F. 2017b. Adsorptive removal of arsenate from aqueous solutions by biochar supported zero-valent iron nanocomposite: Batch and continuous flow tests. Journal of hazardous materials, 322, 172-181.

80. Wang, S., Gao, B., Li, Y., Mosa, A., Zimmerman, A.R., Ma, L.Q., Harris, W.G., Migliaccio, K.W. 2015a. Manganese oxide-modified biochars: Preparation, characterization, and sorption of arsenate and lead. Bioresource technology, 181, 13-17.

81. Wang, S., Gao, B., Zimmerman, A.R., Li, Y., Ma, L., Harris, W.G., Migliaccio, K.W. 2015b. Removal of arsenic by magnetic biochar prepared from pinewood and natural hematite. Bioresource technology, 175, 391-395.

82. Xu, X., Cao, X., Zhao, L. 2013. Comparison of rice husk- and dairy manure-derived biochars for simultaneously removing heavy metals from aqueous solutions: Role of mineral components in biochars. Chemosphere, 92(8), 955-961.

83. Xue, Y., Gao, B., Yao, Y., Inyang, M., Zhang, M., Zimmerman, A.R., Ro, K.S. 2012. Hydrogen peroxide modification enhances the ability of biochar (hydrochar) produced from hydrothermal carbonization of peanut hull to remove aqueous heavy metals: Batch and column tests. Chemical Engineering Journal, 200-202, 673-680.

84. Yang, G.-X., Jiang, H. 2014. Amino modification of biochar for enhanced adsorption of copper ions from synthetic wastewater. water research, 48, 396-405.

85. Yao, Y., Gao, B., Chen, J., Zhang, M., Inyang, M., Li, Y., Alva, A., Yang, L. 2013. Engineered carbon (biochar) prepared by direct pyrolysis of Mg-accumulated tomato tissues: characterization and phosphate removal potential. Bioresource technology, 138, 8-13.

86. Yao, Y., Gao, B., Fang, J., Zhang, M., Chen, H., Zhou, Y., Creamer, A.E., Sun, Y., Yang, L. 2014. Characterization and environmental applications of clay-biochar composites. Chemical Engineering Journal, 242, 136-143.

87. Yu, P., Xue, Y., Gao, F., Liu, Z., Cheng, X., Yang, K. 2016. Phosphorus Removal from Aqueous Solution by Pre-or Post-Modified Biochars Derived from Agricultural Residues. Water, Air, \& Soil Pollution, 227(10), 370.

88. Yuan, J.-H., Xu, R.-K., Zhang, H. 2011. The forms of alkalis in the biochar produced from crop residues at different temperatures. Bioresource technology, 102(3), 3488-3497.

89. Zhang, F., Wang, X., Xionghui, J., Ma, L. 2016. Efficient arsenate removal by magnetitemodified water hyacinth biochar. Environmental Pollution, 216, 575-583.

90. Zhang, M.-m., Liu, Y.-g., Li, T.-t., Xu, W.-h., Zheng, B.-h., Tan, X.-f., Wang, H., Guo, Y.-m., Guo, F.-y., Wang, S.-f. 2015. Chitosan modification of magnetic biochar produced from Eichhornia crassipes for enhanced sorption of $\mathrm{Cr}$ (vi) from aqueous solution. RSC Advances, 5(58), 46955-46964.

91. Zhang, M., Gao, B. 2013. Removal of arsenic, methylene blue, and phosphate by biochar/AlOOH nanocomposite. Chemical Engineering Journal, 226, 286-292.

92. Zhang, M., Gao, B., Varnoosfaderani, S., Hebard, A., Yao, Y., Inyang, M. 2013a. Preparation and characterization of a novel magnetic biochar for arsenic removal. Bioresource technology, 130, 457-462. 
951 93. Zhang, M., Gao, B., Yao, Y., Inyang, M. 2013b. Phosphate removal ability of biochar/MgAl-LDH ultra-fine composites prepared by liquid-phase deposition. Chemosphere, 92(8), 1042-1047.

954

94. Zhang, M., Gao, B., Yao, Y., Xue, Y., Inyang, M. 2012. Synthesis of porous MgObiochar nanocomposites for removal of phosphate and nitrate from aqueous solutions. Chemical Engineering Journal, 210, 26-32.

957 95. Zhao, G., Li, J., Ren, X., Chen, C., Wang, X. 2011. Few-layered graphene oxide nanosheets as superior sorbents for heavy metal ion pollution management. Environmental science \& technology, 45(24), 10454-10462.

96. Zhao, L., Zheng, W., Mašek, O., Chen, X., Gu, B., Sharma, B.K., Cao, X. 2017. Roles of Phosphoric Acid in Biochar Formation: Synchronously Improving Carbon Retention and Sorption Capacity. Journal of Environmental Quality, 46(2), 393-401.

97. Zhou, L., Huang, Y., Qiu, W., Sun, Z., Liu, Z., Song, Z. 2017a. Adsorption Properties of Nano-MnO2-Biochar Composites for Copper in Aqueous Solution. Molecules, 22(1), 173.

98. Zhou, Y., Gao, B., Zimmerman, A.R., Chen, H., Zhang, M., Cao, X. 2014. Biocharsupported zerovalent iron for removal of various contaminants from aqueous solutions.

969 Bioresource technology, 152, 538-542.

99. Zhou, Y., Gao, B., Zimmerman, A.R., Fang, J., Sun, Y., Cao, X. 2013. Sorption of heavy metals on chitosan-modified biochars and its biological effects. Chemical Engineering Journal, 231, 512-518.

100. Zhou, Z., Liu, Y.-g., Liu, S.-b., Liu, H.-y., Zeng, G.-m., Tan, X.-f., Yang, C.-p., Ding, Y., Yan, Z.-1., Cai, X.-X. 2017b. Sorption performance and mechanisms of arsenic (V) removal by magnetic gelatin-modified biochar. Chemical Engineering Journal, 314, 223-

976

977 